\title{
Laboratory, Clinical, and Epidemiological Aspects of Coagulase-Negative Staphylococci
}

\author{
MICHAEL A. PFALLER ${ }^{1.3 *}$ AND LOREEN A. HERWALDT ${ }^{2}$ \\ Veterans Administration Medical Center ${ }^{1}$ and Departments of Medicine ${ }^{2}$ and Pathology, ${ }^{3}$ University of Iowa College of \\ Medicine, Iowa City, Iowa 52242
}

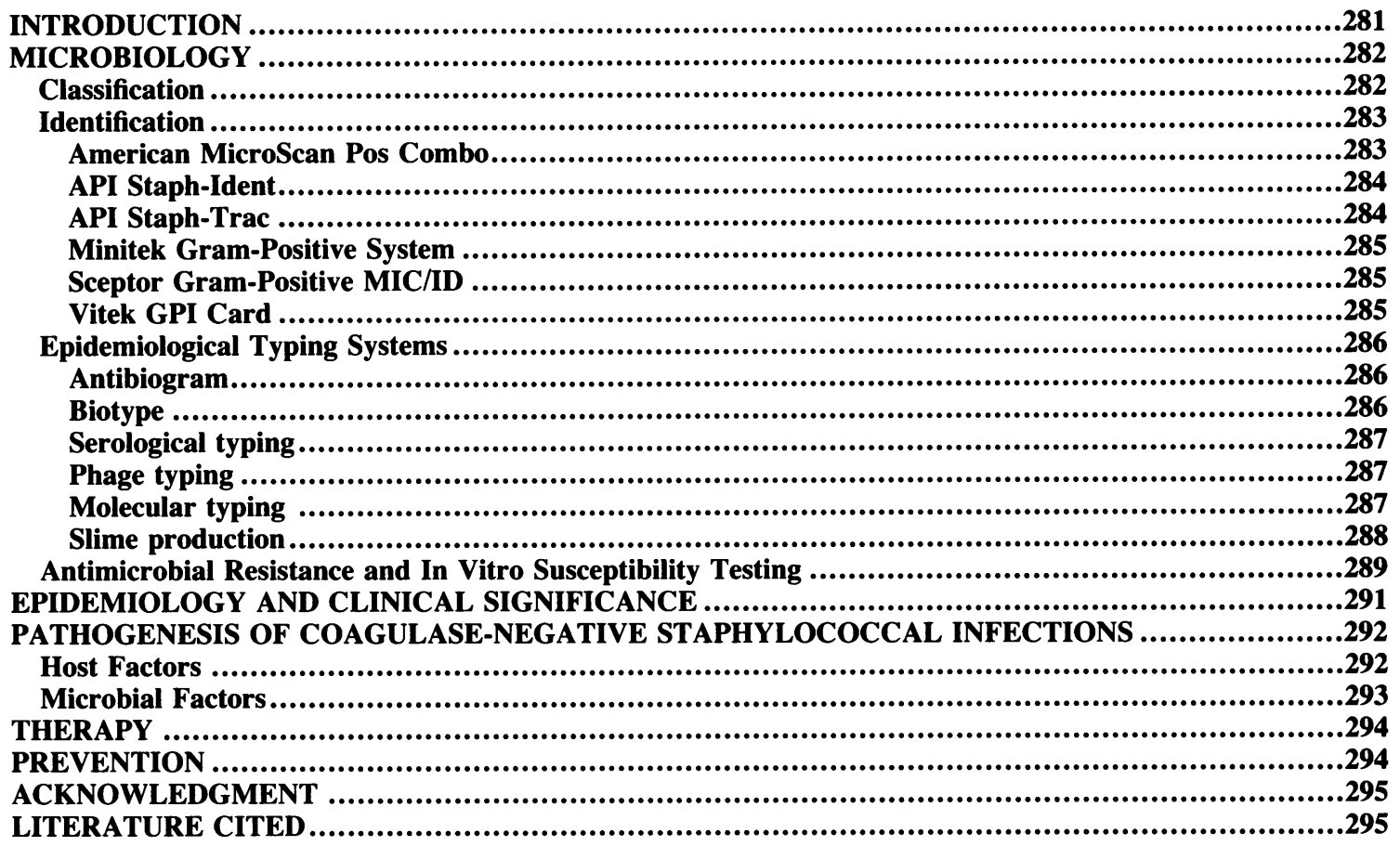

\section{INTRODUCTION}

Coagulase-negative staphylococci are among the most commonly isolated organisms in the clinical microbiology laboratory. The frequent isolation of coagulase-negative staphylococci from blood, other normally sterile body fluids, intravenous catheters, peritoneal dialysates, the various tissues presents a recurring interpretive challenge to both clinical microbiologists and clinicians. Due to their ubiquitous nature and relatively low virulence, coagulase-negative staphylococci long have been considered to be clinically insignificant contaminants when isolated from clinical specimens $(26,27,42,50,59,64,95,139,140,146$; W. M. Dunne, Jr., and T. R. Franson, Clin. Microbiol. Newsl. 8:37-42, 1986). However, in recent years, coagulase-negative staphylococci have become increasingly recognized as important agents of nosocomial infection $(25,34,50,64,67,95,107$, 123, 129, 151, 162, 165, 166; Dunne and Franson, Clin. Microbiol. Newsl. 8:37-42, 1986). Their role as significant pathogens following ophthalmologic $(14,114)$, neurologic $(38,72,135,168)$, and cardiothoracic surgery $(4,7,8,20,30$, $50,73,82,106)$, in immunocompromised patients $(64,67,75$, $88,141,162,166)$, and in patients with prosthetic devices $(3$,

\footnotetext{
${ }^{*}$ Corresponding author.
}

$8,9,19,20,23,30,62,75,81,82,97,120,129,141,154)$ has been well established. Among them, Staphylococcus epidermidis is the most frequently isolated species, occurring in the majority of nosocomial bloodstream infections $(25,26,42$, $64,76,78,107,112,123,151)$. The postulated reasons for the current prevalence and clinical importance of these organisms include their great numbers on the skin, their selection as a result of widespread usage of broad-spectrum antibiotics in the hospital, their ability to adhere to and form biofilms on the surfaces of vascular catheters and other medical devices, and their meager nutritional requirements.

Of particular concern is the rising incidence of bacteremia due to coagulase-negative staphylococci in association with the use of long-term indwelling central venous catheters; $18 \%$ of documented episodes of bacteremia associated with these devices have been attributed to these organisms (141, $162,166)$. The question as to whether infections of these and other implantable prosthetic devices can be successfully treated without removal remains a topic of debate with significant clinical and economic implications $(35,38,64,75$, $95,120,129,136,141,154,162,166,168)$. Thus, it has become increasingly important to distinguish between infective and noninfective isolates of coagulase-negative staphylococci as well as to identify phenotypic traits which may be predictive of therapeutic outcome $(6,8,26,35,38,76$, 
$111,113,168)$. Although no single determinant can be used to identify clinically significant isolates of coagulase-negative staphylococci, certain clinical, epidemiological, and microbiologic criteria should increase suspicion of true infection. The purpose of the present review is to provide a current summary of the microbiologic, clinical, and epidemiologic aspects of coagulase-negative staphylococci. In doing so, we will discuss the rationale and necessity for species identification, the newer identification and epidemiologic typing methods, antimicrobial susceptibility testing, mechanisms of pathogenesis, and prevention and therapy of coagulase-negative staphylococcal infections.

\section{MICROBIOLOGY}

\section{Classification}

Staphylococci are members of the family Micrococcaceae. They are nonmotile, nonsporeforming, gram-positive, facultatively anaerobic, clustering cocci that produce catalase. The distinction between coagulase-negative staphylococci and micrococci is important since some species of coagulase-negative staphylococci are important opportunistic and nosocomial pathogens, whereas, at present, micrococci are considered harmless saprophytes. Staphylococcus species are delineated from Micrococcus species on the basis of (i) glucose fermentation (positive for most staphylococci and negative for most micrococci) $(12,43,132)$, (ii) acid production from glycerol (positive for most staphylococci and negative for most micrococci) $(12,89,111)$, (iii) susceptibility to lysostaphin (staphylococci) $(12,89,111$, $132)$, (iv) susceptibility to lysozyme (micrococci) $(12,89$, 132), (v) modified oxidase and benzidine tests (negative in most staphylococci and positive in micrococci) (45), (vi) susceptibility to furazolidine (staphylococci) $(11,12)$, and (vii) susceptibility to bacitracin (micrococci) (44). Finally, differences in peptidoglycan and teichoic acid composition and deoxyribonucleic acid (DNA) base composition provide a clear distinction between staphylococci and micrococci and confirm the results of the more simple tests listed above $(12,132-134,144)$. At present, there are 23 recognized species of staphylococci, 21 of which are coagulase negative, and 12 of them are found as part of the normal flora of humans $(88-90,110,111,132$; W. E. Kloos, Clin. Microbiol. Newsl. 4:75-79, 1982). The subgeneric structure and biochemical diversity of Staphylococcus is extremely complex and has been extensively discussed in several recent reviews (87, 90, 92, 110, 132; Kloos, Clin. Microbiol. Newsl. 4:75-79, 1982).

Originally, of all the staphylococci, only Staphylococcus aureus was considered pathogenic and was delineated from the other species on the basis of coagulase production, mannitol fermentation, and the presence of protein $A$ on the cell wall surface. All other species were grouped under the species designation $S$. albus, which was subsequently changed to $S$. epidermidis, and were considered nonpathogens $(64,89,111$; Dunne and Franson, Clin. Microbiol. Newsl. 8:37-42, 1986, Kloos, Clin. Microbiol. Newsl. 4:7579, 1982). The work of Kloos, Schleifer, and colleagues (87-92, 132-134; Kloos, Clin. Microbiol. Newsl. 4:75-79, 1982) redefined coagulase-negative staphylococci so that 21 species are now recognized (Table 1) based on extensive morphological, physiological, and biochemical characters and cell wall peptidoglycan and teichoic acid composition. These relationships were subsequently confirmed by DNADNA hybridization and comparative immunological studies
TABLE 1. Classification of coagulase-negative staphylococci and their pathogenic significance

\begin{tabular}{|c|c|}
\hline Species & $\begin{array}{l}\text { Pathogenic } \\
\text { significance }\end{array}$ \\
\hline \multicolumn{2}{|c|}{ S. epidermidis species group } \\
\hline S. epidermidis & Common \\
\hline S. haemolyticus & Uncommon \\
\hline S. hominis & Uncommon \\
\hline S. saccharolyticus & Uncommon \\
\hline S. warneri & Uncommon \\
\hline S. capitis & Rare/undetermined \\
\hline S. caprae $^{a, b}$ & Rare/undetermined \\
\hline S. auricularis ${ }^{a}$ & Rare/undetermined \\
\hline
\end{tabular}

S. saprophyticus species group
S. saprophyticus
S. cohnii
S. xylosus
S. arlettae ${ }^{a, b}$
S. equorum ${ }^{a . b}$
S. gallinarum $^{a, b}$
S. kloosii ${ }^{a, b}$

Common

Uncommon

Rare/undetermined Rare/undetermined Rare/undetermined Rare/undetermined Rare/undetermined

\section{S. simulans species group}

S. simulans

S. carnosus $^{b}$

Uncommon

Rare/undetermined

S. sciuri species group

S. sciuri ${ }^{b}$

Rare/undetermined

S. lentus ${ }^{b}$

Rare/undetermined

Unspecified species group

$S$. caseolyticus ${ }^{b}$

S. hyicus $^{c}$

Rare/undetermined Rare/undetermined

${ }^{a}$ Species group designation is questionable.

${ }^{b}$ Isolated from animals or animal products.

c Coagulase-variable veterinary pathogen.

$(1,89,90,110,111,132-134,144)$. Based on this work, the genus Staphylococcus can be divided into several species groups (Table 1 ). The $S$. epidermidis species group is the largest, containing $S$. epidermidis, $S$. haemolyticus, $S$. hominis, $S$. saccharolyticus, $S$. warneri, $S$. capitis, and $S$. caprae. The $S$. saprophyticus species group consists of $S$. saprophyticus, $S$. cohnii, and $S$. xylosus. The $S$. simulans species group is composed of $S$. simulans and $S$. carnosus, and the $S$. sciuri species group contains $S$. sciuri and $S$. lentus. $S$. auricularis is closely associated with the $S$. epidermidis species group, and $S$. arlettae, $S$. equorum, $S$. gallinarum, and $S$. kloosii are associated with the $S$. saprophyticus species group. S. caseolyticus and $S$. hyicus cannot be accommodated in any of the species groups. Of the coagulase-positive staphylococci, $S$. aureus is closely associated with the $S$. epidermidis species group and $S$. intermedius cannot be accommodated in any of the existing species groups.

Most of the coagulase-negative staphylococci are common inhabitants of the skin and mucous membranes. In studies of the ecology of staphylococci on human skin, Kloos and co-workers (87-90; Kloos, Clin. Microbiol. Newsl. 4:75-79, 1982 ) found that $S$. aureus and $S$. epidermidis were the predominant and persistent staphylococci isolated from the nares whereas $S$. epidermidis and $S$. hominis predominated on the skin of the axillae, head, legs, and arms. S. capitis was often isolated from the head, face, ear, and arms, $S$. auricularis was isolated from the ear, and $S$. haemolyticus was isolated from the head, legs, and arms. S. simulans, $S$. 
xylosus, S. cohnii, S. saprophyticus, and S. warneri were only occasionally isolated from skin. Of the remaining coagulase-negative staphylococci, $S$. saccharolyticus is rarely isolated from human skin and $S$. caprae, $S$. arlettae, $S$. equorum, $S$. gallinarum, $S$. kloosii, $S$. carnosus, $S$. sciuri, $S$. lentus, $S$. caseolyticus, and $S$. hyicus are isolated predominantly or exclusively from animals or animal products (89).

Presently it is clear that, in addition to $S$. aureus, those staphylococci of documented clinical importance are $S$. epidermidis and $S$. saprophyticus. In studies that have attempted to correlate species identification with clinical significance, $S$. epidermidis has accounted for the majority $(>75 \%)$ of the coagulase-negative staphylococcal isolates $(9$, $25,26,34-37,50,59,76,77,82,122,124,129,140)$. This is most likely due to the overwhelming preponderance of $S$. epidermidis on the skin $(88-91,94)$; however, $S$. epidermidis may also possess virulence factors absent in other coagulase-negative staphylococci $(9,26,27,53,55,56,98,163) . S$. saprophyticus appears to be a significant cause of urinary tract infections in young women, but has rarely been implicated in other types of infections $(50,77,87,89,101,140$; Dunne and Franson, Clin. Microbiol. Newsl. 8:37-42, 1986; Kloos, Clin. Microbiol. Newsl. 4:75-79, 1982). Previous recognition of this group of organisms as significant pathogens may have been obscured due to incomplete or inaccurate laboratory identification. Other species of coagulasenegative staphylococci, including $S$. hominis, $S$. haemolyticus, and $S$. simulans, have each been isolated from 5 to $20 \%$ of the total human infections attributed to these organisms $(67,77,89,140$; Dunne and Franson, Clin. Microbiol. Newsl. 8:37-42, 1986; Kloos, Clin. Microbiol. Newsl. 4:7579, 1982). S. auricularis, $S$. capitis, $S$. cohnii, $S$. saccharolyticus, $S$. warneri, and $S$. xylosus have rarely, if ever, been reported to cause human infection.

\section{Identification}

Although the usefulness of exact species identification of coagulase-negative staphylococci in the clinical laboratory has not met with universal agreement, most microbiologists and clinicians recognize the need to identify $S$. epidermidis and $S$. saprophyticus with a high degree of accuracy $(6,9$, 26, 39, 40, 64, 76, 95, 100, 101, 111, 139; Dunne and Franson, Clin. Microbiol. Newsl. 8:37-42, 1986). This can be accomplished on the basis of colony morphology, coagulase and phosphatase activities, acid production from D-mannitol, D-trehalose, maltose, sucrose, and D-xylose, and novobiocin susceptibility $(89,91,92,110,132)$. The identification of other species of coagulase-negative staphylococci can be accomplished with these tests plus the determination of acid production from certain additional carbohydrates and certain enzyme activities $(89,91,92,110,132)$. Unfortunately, because the conventional methods of Kloos and Schleifer (91) are considered too slow and cumbersome for use in the routine clinical microbiology laboratory and because $S$. epidermidis is the predominant pathogen among the coagulase-negative staphylococci, many clinical laboratories routinely report all coagulase-negative staphylococci as $S$. epidermidis without performing any biochemical testing other than a coagulase test. Clearly this is not strictly correct and, given the emergence of coagulase-negative staphylococci as major nosocomial pathogens, may result in confusion and misinterpretation of culture results. If species identification is not performed, then the isolate should be reported as a coagulase-negative Staphylococcus sp. Recently, Stevens and Jones (150) reported that, by using a single agar plate with medium containing trehalose, mannitol, and phenolphthalein diphosphate, they could differentiate significant clinical isolates of $S$. epidermidis from other species of coagulase-negative staphylococci with a sensitivity of $100 \%$, specificity of $89.9 \%$, and positive predictive value of $94.8 \%$. By also testing for resistance to a $5-\mu \mathrm{g}$ novobiocin disk on the same plate, they differentiated $S$. saprophyticus, with a sensitivity of $100 \%$, specificity of $97.1 \%$, and positive predictive value of $83.9 \%$. This approach stops short of complete species identification of all isolates and offers a rapid, inexpensive means of delineating the two most important coagulase-negative staphylococcal pathogens in the clinical laboratory. More detailed biochemical characterization and identification may be accomplished in the busy clinical laboratory by using one of several commercially available identification kits described below.

Despite considerable controversy over the need to routinely identify coagulase-negative staphylococci to species (42, 64, 76, 89, 111, 139, 140, 146; Dunne and Franson, Clin. Microbiol. Newsl. 8:37-42, 1986), there are several positive reasons to encourage more widespread species identification of these organisms. In addition to the value of having an exact etiological diagnosis, identification increases the knowledge of the pathogenicity of the various species of coagulase-negative staphylococci, provides useful epidemiologic information, and contributes to the predictive value of an isolate being of clinical significance versus being a contaminant $(6,26,35,76)$. The results of Ishak et al. (76) demonstrate that knowledge of the species of coagulasenegative staphylococci and its ability to produce slime may assist the clinician in evaluating the clinical significance of such an isolate growing from a blood culture. They found that the isolation of $S$. epidermidis sensu stricto from blood, particularly if it was slime positive, was highly predictive of clinical infection whereas the isolation of any other species of coagulase-negative staphylococci was not (76). Similarly, Archer et al. (6) demonstrated that delineation of individual strains, as well as species, of coagulase-negative staphylococci may be useful in distinguishing infective versus noninfective isolates for diagnostic purposes and as an epidemiologic tool for investigating infections.

The commercial availability of rapid and miniaturized identification systems provides virtually every clinical laboratory with the capability of identifying coagulase-negative staphylococci to the species level. Several manufacturers of commercial kit identification systems or automated instruments have products that are relatively simple and rapid and allow the identification of coagulase-negative staphylococcal species with an accuracy of 70 to $>90 \%$ when combined with coagulase testing and novobiocin susceptibility $(2,39,55,58$, $61,75,89,92-94,116,130,141)$. The systems currently available are presented in Table 2 and include American MicroScan Pos Combo panel (American Hospital Supply Corp., Mahwah, N.J.), API Staph-Ident System (Analytab, Inc., Plainview, N.Y.), API Staph-Trac (Analytab), Minitek (BBL Microbiology Systems, Cockeysville, Md.), Sceptor Gram-Positive MIC/ID (Johnston Laboratories, Towson, Md.), and the Vitek Gram-Positive Identification (GPI) Card (Vitek Systems, Inc., Hazelwood, Mo.).

American MicroScan Pos Combo. The American MicroScan Pos Combo panel is designed for the identification and susceptibility testing of different staphylococcal and streptococcal isolates as well as certain species of other grampositive genera. The panels are supplied and stored frozen and contain a total of 27 miniaturized tests, 18 of which are utilized for the identification of staphylococci and micro- 
TABLE 2. Summary of commercially available coagulase-negative staphylococcal identification systems

\begin{tabular}{lcccc}
\hline \multicolumn{1}{c}{ Test system } & $\begin{array}{c}\text { Time to } \\
\text { final identifi- } \\
\text { cation (h) }\end{array}$ & $\begin{array}{c}\text { No. of } \\
\text { species } \\
\text { identified }\end{array}$ & $\begin{array}{c}\% \\
\text { Correct }\end{array}$ & Reference(s) \\
\hline American MicroScan & $18-48$ & 11 & $79-95$ & 74 \\
API Staph-Ident & 5 & 12 & $65->90$ & 60,92 \\
API Staph-Trac & 24 & 14 & $87->90$ & 54,57 \\
Minitek & $18-24$ & 12 & $86-92$ & 31 \\
Sceptor & $18-24$ & 10 & $91^{a}$ & $-^{a}$ \\
Vitek GPI & $4-12$ & $5^{b}$ & $67-83^{b}$ & 2,60 \\
\hline
\end{tabular}

${ }^{a}$ Skulnick et al., Abstr. Annu. Meet. Am. Soc. Microbiol. 1987.

${ }^{b}$ Published data based on old GPI card. Updated system identifies up to 12 species of coagulase-negative staphylococci plus $S$. aureus, $S$. intermedius, and $S$. hyicus (coagulase positive)

cocci. Thawed panels are inoculated with $10^{5}$ colonyforming units per $\mathrm{ml}$ and incubated for 18 to $48 \mathrm{~h}$ at $35^{\circ} \mathrm{C}$ in air and read by visual inspection or on the MicroScan instrument (autoSCAN-4). The biochemical profile produces a six-digit code or biotype number. Acceptable identifications are those in which the probability value is $>85 \%$. The data base allows the identification of up to 11 species of coagulase-negative staphylococci. This system has been evaluated by several groups versus the conventional system of Kloos and Schleifer (91) and correctly identifies between 79 and $95 \%$ of clinical isolates of coagulase-negative staphylococci depending on the incubation time used $(74 ;$ J. A. Daly, K. C. Seskin, and W. M. Gooch III, Program Abstr. 26th Intersci. Conf. Antimicrob. Agents Chemother., abstr. no. 253, 1986; M. Skulnick, M. P. Patel, S. T. F. Lai, and D. E. Low, Abstr. Annu. Meet. Am. Soc. Microbiol. 1987, C103, p. 340). Recently, Hussain et al. (74) reported their evaluation of the MicroScan system with 175 clinical isolates of coagulase-negative staphylococci. Overall, the MicroScan system correctly identified $83.4 \%$ of the isolates. The system correctly identified $97.6 \%$ of $S$. epidermidis and $97.1 \%$ of $S$. saprophyticus isolates after $48 \mathrm{~h}$ of incubation. Most of the misidentification occurred in association with $S$. hominis (11 of 17) and $S$. warneri ( 7 of 23). The major disadvantage of the system was that, for $112(64 \%)$ of the isolates, the identification was not complete until after $48 \mathrm{~h}$ of incubation. The advantages of the system are that the plates can be read either visually or automatically with the autoSCAN-4 reader and that the panels also test for the minimal inhibitory concentrations of 12 antibiotics. The simultaneous determination of both "biotype" and "antibiogram" may be useful in delineating specific strains of coagulase-negative staphylococci for clinical and epidemiologic purposes $(26,168)$.

API Staph-Ident. The API Staph-Ident System consists of a series of 10 microcupules containing dehydrated substrates, nutrient media, or both for the identification of 12 species of coagulase-negative staphylococci and $S$. aureus. The strips are inoculated with a suspension of organisms at a density equal to a no. $3 \mathrm{McF}$ arland standard, incubated for $5 \mathrm{~h}$ at $35^{\circ} \mathrm{C}$ in air, and read visually. Positive color reactions are converted to a four-digit profile for species identification according to instructions of the manufacturer. It is recommended that the additional tests of novobiocin susceptibility (5- $\mu \mathrm{g}$ disk) and coagulase activity be used to identify more accurately certain strains of $S$. saprophyticus, $S$. cohnii, $S$. hominis, and $S$. aureus. The Staph-Ident System has been evaluated by several investigators and correctly identifies between 65 and $>90 \%$ of coagulase-negative staphylococcal isolates depending on the number and type of additional tests performed and the proportion of phosphatase-negative $S$. epidermidis included in the study $(26,32,39,57,60,74,89$, $92,168)$. Grasmick et al. (60) reported that the Staph-Ident System correctly identified $65.3 \%$ of 190 coagulase-negative staphylococci, including only $74.5 \%$ of $S$. epidermidis, without further testing. They found that all $S$. epidermidis isolates requiring further testing had negative phosphatase reactions, but none of these isolates was identified with the recommended differential tests. Overall, $24.8 \%$ of the $S$. epidermidis isolates in their study were phosphatase negative. They suggest that further differential tests such as anaerobic growth in thioglycolate broth should be used to differentiate phosphatase-negative $S$. epidermidis from $S$. hominis. In contrast to the findings of Grasmick et al. (60), Kloos and Wolfshohl (92) found $>90 \%$ agreement between the API Staph-Ident and conventional methods for coagulase-negative staphylococci; however, only $7 \%$ of the $S$. epidermidis isolates used in their study were phosphatase negative versus $24.8 \%$ in the study of Grasmick et al. (60). Thus, the proportion of phosphatase-negative $S$. epidermidis isolates included in an evaluation of this system may markedly influence the overall results of the evaluation. The difficulty in the identification of phosphatase-negative $S$. epidermidis by the Staph-Ident System has been noted vy several investigators $(32,39,57,74,168)$. In general, the advantages of the Staph-Ident system are that (i) it is easy to inoculate, (ii) it is rapid $(5 \mathrm{~h})$, (iii) it requires no special equipment, and (iv) the data base includes 12 species of coagulase-negative staphylococci. The disadvantages of the system are that (i) the color reactions are difficult to interpret, (ii) it requires a heavy inoculum, (iii) supplemental testing is frequently required, and (iv) the supplemental tests recommended are frequently not useful in obtaining an accurate identification.

API Staph-Trac. The API Staph-Trac system is a system for the identification of 14 coagulase-negative staphylococcal species of human and veterinary origin and for differentiation between Staphylococcus and Micrococcus species. The Staph-Trac kit consists of a series of microcupules containing dehydrated substrates for the performance of 19 different biochemical tests and a negative control. The microcupules are inoculated with a suspension of organisms with opacity equivalent to a no. $2 \mathrm{McF}$ arland standard, incubated for $24 \mathrm{~h}$ in air at $35^{\circ} \mathrm{C}$, and read visually following the addition of appropriate indicator reagents. Reactions are converted into a seven-digit profile number for species identification. This system may require additional tests such as lysostaphin susceptibility to differentiate staphylococci from micrococci. In published studies, the Staph-Trac system has been shown to accurately identify between 87 and $>90 \%$ of coagulasenegative staphylococci. An early study by Gemmell and Dawson (54) reported that the Staph-Trac system identified $>90 \%$ of coagulase-negative staphylococci to species level. Likewise, Giger et al. (57) found the overall accuracy of the system to be $88.3 \%$ ( $96.2 \%$ for $S$. epidermidis) when testing 120 clinical isolates of these organisms. The most commonly misidentified $(50 \%)$ species in this study was $S$. warneri. Most recently, Skulnick et al. (Abstr. Annu. Meet. Am. Soc. Microbiol. 1987) demonstrated an $87 \%$ agreement with the reference method of Kloos and Schleifer (91) for 115 clinically significant isolates of coagulase-negative staphylococci. Of note was their finding that 14 of 15 misidentifications were due to lack of fermentation of $\mathrm{N}$-acetylglucosamine, resulting in the misidentification of isolates of $S$. haemolyticus. This is in contrast to the results of Giger et al. (57), who reported a $73.3 \%$ accuracy in identifying $S$. haemolyticus 
and found no single test or group of tests responsible for misidentification of the various species of coagulase-negative staphylococci.

Minitek Gram-Positive System. The Minitek Gram-Positive System is designed for the identification of 12 species of coagulase-negative staphylococci, $S$. aureus, and certain streptococcal and micrococcal species. The Minitek system consists of a plastic multiwell tray that holds as many as 20 paper disks impregnated with different substrates or biochemicals. A total of 21 tests are included in the system. The inoculum is prepared by picking several colonies from an overnight culture on sheep blood agar, emulsifying the organisms in $1.5 \mathrm{ml}$ of gram-positive inoculum broth, and adjusting the density of the suspension to that of a no. 1 McFarland standard. All wells are inoculated with $50 \mu \mathrm{l}$ of inoculum suspension (the arginine well requires $100 \mu \mathrm{l}$ ), overlaid with sterile mineral oil (with the exception of esculin, nitrate, and phosphatase wells), and incubated in a humidified chamber at $35^{\circ} \mathrm{C}$ in air for 18 to $24 \mathrm{~h}$. The plates are read visually, and the reactions are translated into a seven-digit profile number. Several supplemental tests including coagulase activity, hemolysis, and novobiocin susceptibility are recommended by the manufacturer for more accurate identification of $S$. saprophyticus, $S$. haemolyticus, $S$. hominis, and $S$. aureus. A recent study of Crouch et al. (32) demonstrated an $86 \%$ overall agreement between Minitek and the reference method of Kloos and Schleifer (91). The Minitek system correctly identified $96 \%$ of the $S$. epidermidis isolates in this study. The Minitek errors most commonly involved the misidentification of $S$. warneri $(60 \%$ misidentified) or $S$. hominis (60\% misidentified); however, each of the misidentifications was due to a number of incorrect reactions and was not the result of any consistent error. The Minitek system compares favorably with several of the commercially available staphylococcal identification systems and appears to be a practical, reliable method for species identification of coagulase-negative staphylococci. One advantage of the Minitek system is its flexibility. Different tests can be performed by adding or changing the types of biochemical disks, and the same methodology can be used to identify certain gram-negative bacilli, Neisseria species, and yeasts. Additional studies with different substrates may enlarge or enhance the data base with resulting improved accuracy for species identification of coagulasenegative staphylococci.

Sceptor Gram-Positive MIC/ID. The Sceptor Gram-Positive MIC/ID panel is a microdilution system for the combined susceptibility testing and identification of 11 species of Staphylococcus (10 coagulase negative), 7 species of Micrococcus, and 22 species of Streptococcus. The dehydrated panels have 24 wells designated for biochemical tests and the remainder designated for susceptibility tests. The Sceptor system is available as a manual or semiautomated system. The semiautomated system consists of an automated preparation station and a semiautomated reader-recorder. The preparation station automatically dispenses $100 \mu \mathrm{l}$ of the inoculum suspension into each well of the microdilution panel in $<1 \mathrm{~min}$. The reader-recorder instrument facilitates the visual reading and manual recording of test results. The test inoculum for the Sceptor system is prepared by growing the test organism in broth at $35^{\circ} \mathrm{C}$ to a density approximating a $0.5 \mathrm{McF}$ arland standard, diluting this suspension $1: 100$, and inoculating the test panels. The panels are incubated at $35^{\circ} \mathrm{C}$ for 18 to $24 \mathrm{~h}$ and then read visually. The Sceptor Gram-Positive MIC/ID panel was recently evaluated by Skulnick and co-workers (Abstr. Annu. Meet. Am. Soc.
Microbiol. 1987). The Sceptor system correctly identified $91 \%$ of 115 clinically significant isolates of coagulase-negative staphylococci which had previously been identified by the method of Kloos and Schleifer (91). Overall, 4 of the 10 misidentifications with the Sceptor system were due to failure of the data base to recognize lactose-variable $S$. haemolyticus. The performance of the Sceptor system was comparable to that of several other staphylococcal identification systems, and the accuracy may be improved by minor alterations to the existing data base. Similar to the MicroScan system described above, the simultaneous determination of biotype and antibiogram with the Sceptor system may be advantageous.

Vitek GPI Card. The Vitek AutoMicrobic System utilizes a GPI card to identify staphylococci, streptococci, and certain other gram-positive bacteria. The GPI card contains 27 biochemical wells and 1 positive and 2 negative growth control wells. In addition, a Gram stain, catalase test, coagulase test, and hemolysis results (beta versus non-beta) are required for the accurate performance of the GPI card. The inoculum suspension equivalent to a $0.5 \mathrm{McF}$ arland standard is prepared in $0.45 \%$ saline and inoculated into the GPI card with a transfer tube and the filling module of the AutoMicrobic System. During incubation in the readerincubator module, the computer automatically analyzes the reactions of the GPI card, and the identification is automatically printed out from the data terminal. The incubation period for the GPI card varies according to the growth rate of the inoculated organism. Identification for most staphylococci will be made after incubation for 4 to $13 \mathrm{~h}$ (average, $10.8 \mathrm{~h}$ ). Currently, the published studies of the GPI card have used a card and software capable of identifying only $S$. epidermidis, $S$. saprophyticus, $S$. hominis, $S$. haemolyticus, $S$. simulans, and $S$. aureus (Table 2$)(2,60,128)$. Recently, the data base for the GPI card has been expanded to allow the identification of up to 12 species of coagulase-negative staphylococci plus $S$. aureus, $S$. intermedius, and $S$. hyicus (coagulase positive); however, evaluations of the expanded data base have not been published, and thus the present discussion is limited to evaluation of the old GPI card and data base. Published evaluations indicate that the GPI card correctly identifies between 67 and $83 \%$ of coagulase-negative staphylococcal isolates. In an early study, Ruoff et al. (128) reported that the GPI card correctly identified $79 \%$ of 98 coagulase-negative staphylococci, including $88 \%$ of $S$. epidermidis and $100 \%$ of $S$. saprophyticus. Almeida et al. (2) found that the GPI card was only $67.3 \%$ accurate in identifying 150 clinical coagulase-negative staphylococci isolates. The GPI card was most accurate in identifying $S$. epidermidis $(95 \%$ correct) and $S$. saprophyticus $(87.1 \%$ correct) and was least able to identify $S$. hominis ( $26.7 \%$ correct). In agreement with the findings of Ruoff et al. (128), these investigators noted difficulty in correctly identifying the less commonly isolated species by the GPI card. Those species not included in the data base were assigned an incorrect species designation instead of being included under Staphylococcus species. Finally, Grasmick et al. (60) reported that the GPI card correctly identified $83.2 \%$ of 190 coagulasenegative staphylococcal isolates and $95.9 \%$ of $145 \mathrm{~S}$. epidermidis isolates. Based on these studies, the advantages of the Vitek GPI system are (i) automated reading and interpretation, (ii) rapid time to identification, and (iii) small inoculum requirement. The disadvantages are (i) limited data base (expanded in the most recent version of the GPI card) and (ii) requirement for expensive instrumentation which may also take up extra laboratory space. 
It is apparent from the preceding discussion that there are several commercially available systems for rapid and convenient species identification of clinical isolates of coagulasenegative staphylococci. Although the accuracy of these systems varies considerably between the published studies, in general they are all quite accurate in identifying $S$. epidermidis and $S$. saprophyticus, the two most important coagulase-negative staphylococcal pathogens. Although the need for identifying most clinical isolates of coagulasenegative staphylococci to species remains controversial, the availability of these identification systems will facilitate further investigative efforts in this area $(95,111,139)$.

\section{Epidemiological Typing Systems}

As noted above, coagulase-negative staphylococci are universally found on human skin and several species can be detected on any given individual; however, $S$. epidermidis sensu stricto is the most common species isolated in the clinical laboratory. When a species that appears to be the cause of infection is a frequent or universal member of the normal flora or the environment, simple species identification is no longer useful in distinguishing between infection and colonization or in tracing the source of the infecting organism. The ubiquitous nature of $S$. epidermidis and its expanding role as a major nosocomial pathogen has necessitated the development of methods of strain delineation within species for use as epidemiological and diagnostic tools. The rationale for strain delineation is that repeated isolation of an organism with identical markers from one or more patients suggests that the organism has originated from a single clone and therefore is highly likely to be causing infection (individual patient) or has been transmitted from patient to patient from a common source or by a common mechanism or both. Several different epidemiological typing methods have been applied in studies of coagulase-negative staphylococci. These include antimicrobial susceptibility profiles (antibiogram), biochemical profiles (biotype), serological typing, bacteriophage susceptibility patterns (phage typing), and DNA typing methods (plasmid profiling, restriction endonuclease analysis of plasmid and chromosomal DNA, and DNA hybridization). The timely delineation of specific phenotypic (or genotypic) profiles of coagulasenegative staphylococci by one or more of the above methods will provide the basis for studies designed to answer important epidemiologic and pathogenetic questions, including (i) the site of origin (reservoir) of organisms causing nosocomial infections, (ii) the frequency and mechanism of patient-topatient or hospital staff-to-patient spread of coagulase-negative staphylococcal isolates causing nosocomial infection, and (iii) the importance of strain variation in the pathogenesis of coagulase-negative staphylococcal infection. In addition, in individual patients such data will be useful in providing evidence that separate clinical isolates are identical and thus likely to be true pathogens rather than contaminants $(6,26,35,76,111,112)$. It is important to emphasize that our knowledge concerning the origins, reservoirs, and modes of transmission of coagulase-negative staphylococci is extremely limited and that the application of epidemiologic typing methods is essential in answering these questions. The information gained from studies that use useful typing methods will result in improved methods of prevention, diagnosis, and therapy, as well as increased understanding of the pathogenesis of coagulase-negative staphylococcal infections. The utilization of these typing methods to study these organisms has recently been reviewed in detail by Parisi
$(111,112)$; thus, only selected aspects will be discussed below.

Antibiogram. The antimicrobial susceptibility profile or antibiogram has been used extensively to distinguish strains of various organisms, including clinical isolates of coagulasenegative staphylococci $(9,25,26,50,64,73,100,106,111$, $112,114,122,124)$. Because antimicrobial susceptibility testing is routinely performed in the clinical microbiology laboratory according to standardized procedures, the antibiogram is readily available and is frequently used by clinicians to identify clinically significant strains of $S$. epidermi$d i s$ and other coagulase-negative staphylococci as well as for epidemiological purposes. In general, the presence of a strain with a unique antibiogram can provide a marker for detecting similar strains. Unfortunately, several problems with the use of the antibiogram as an epidemiological marker limit its usefulness as a means of typing coagulase-negative staphylococci. The major problems with this method of strain delineation follow: (i) a large proportion of nosocomial isolates of coagulase-negative staphylococci are resistant to multiple antibiotics, thus limiting the number of unique antibiograms observed in a given institution $(3,7,25,26,50$, $63,73,100,111,122,146,168$ ); (ii) considerable day-to-day variation in the antibiogram may result from analytical variation in the susceptibility testing method $(6,26,106$, 111); (iii) the expression of antibiotic resistance in some strains of coagulase-negative staphylococci may be unstable (106) In a statistical analysis of several C-NS typing systems, coagulase-negative staphylococcal Christensen et al. (26) reported an assignment probability of $P=0.303$ to 0.897 for the antibiogram alone, indicating that this method could not reliably categorize two strains of coagulase-negative staphylococci as the same or different.

Biotype. Similar to the antibiogram, the generation of a biochemical profile or biotype has frequently been used, alone or in combination with the antibiogram, as a means of distinguishing strains of coagulase-negative staphylococci $(9,10,15,26,39,50,72,73,100,106,111,112,114,168)$. Prior to the taxonomic work of Kloos and Schleifer (91) and the development of the rapid commercially available identification system described above, several different biotyping systems were proposed for both taxonomic and epidemiologic purposes $(10,15,26,50,72,73,100,111)$. These systems were based on numerous biochemical and physiologic tests and included the systems of Baird-Parker (10), Bentley et al. (15), Holt (72), and several others $(50,73,111)$. Of the various biotyping schemes, only those of BairdParker and Bentley have received much attention. Unfortunately, the methods and tests used in these systems have not been standardized and very few comparative studies have been performed. In general, these biotyping schemes have been ineffective in epidemiological studies due to the small number of recognized phenotypes. With the widespread availability of the rapid, miniaturized commercial identification systems described above, several investigators have attempted to use the biochemical profiles generated in the identification process as epidemiological markers $(9,26,39$, $106,114,168)$. The two systems most commonly used have been the API Staph-Ident and the API Staph-Trac. The major problem with the use of either of these systems in epidemiological studies is that they were developed for the purpose of species identification and not subspecies or strain delineation. As a result, the number of different biotypes for any given species of coagulase-negative staphylococci is limited and the majority of clinical isolates are contained within only a few distinct biotypes $(26,39,106,111,114$, 
168). In a study of nosocomial bloodstream isolates, Christensen et al. (26) reported that biotyping alone with the Staph-Ident system could not reliably delineate strains of $S$. epidermidis (assignment probability, $P=0.346$ ) but that the combination of biotype plus the antibiogram greatly enhanced the discriminating power of both systems (assignment probability $P=0.037$ ). Mickelsen et al. (106) found that the biotypes obtained with the Staph-Ident system were not reproducible because each of five isolates of $S$. epidermidis gave a different biocode when tested on two different occasions. Others have reported similar limitations to the use of these systems alone in epidemiologic studies $(39,111$, $114,168)$. Of particular interest with regard to biotyping coagulase-negative staphylococci is the recent report of Younger et al. (168) that phosphatase-negative strains of $S$. epidermidis may be a particularly virulent type of coagulasenegative staphylococci. They found that $20 \%$ of their cerebrospinal fluid shunt pathogens and none of the contaminants belonged to this subgroup. The pathogenic importance of this subgroup may have been obscured in the past due to the misidentification of phosphatase-negative $S$. epidermidis as $S$. hominis by the API Staph-Ident system. Additional studies of isolates from other sites of infection and from other institutions are warranted to confirm this important observation.

Serological typing. Serological typing has been useful as an epidemiological tool in the investigation of a variety of infectious diseases; however, it has not been well developed for use with coagulase-negative staphylococci $(1,111,117$, $132,134,155)$. As might be expected, this is largely due to the difficulties of preparing specific antisera and the standardization of typing methods. Although $S$. aureus and $S$. epidermidis clearly share several group antigens, crossabsorption studies have demonstrated that $S$. epidermidis has its own set of type agglutinogens $(1,132,134,155)$. This information has allowed for the development of typing sera, and serotyping, in combination with biotyping, has been applied successfully in a limited number of studies $(117,132$, $134,155)$. Given the availability of other typing systems for coagulase-negative staphylococci, serotyping does not appear to have much of a role in epidemiological studies of these organisms.

Phage typing. The most established system for epidemiological typing of staphylococci is the determination of bacteriophage susceptibility patterns (phage typing). Although an international set of typing phages has been established for $S$. aureus, the application of this set to $S$. epidermidis was disappointing as these organisms were rarely lysed by phages isolated from $S$. aureus $(111,112)$. Currently there are four major phage-typing sets for coagulase-negative staphylococci, including those of Van Boven et al. (158), Pulverer et al. (125), Dean et al. (36) and Parisi and coworkers $(115,145,152)$. These typing sets have been widely used for strain identification either alone or in combination with other methods with varying degrees of success $(26,37$, $50,73,106,111,112,114,152)$.

Parisi (111) has described three characteristics that a phage-typing system should possess to be useful in epidemiological studies (i) It should type or lyse a large proportion of the strains. (ii) It should be reproducible; different isolates derived from the same bacterial clone should give essentially identical reactions. (iii) It should discriminate epidemiologically related strains from unrelated strains. An international collaborative study was performed to assess the existing coagulase-negative staphylococcal phage-typing systems with regard to the above characteristics. Four hundred isolates of $S$. epidermidis from serious infections, representing a minimum of 271 independent strains, were tested by 12 laboratories for susceptibility in their phage-typing systems (37). The results demonstrated that none of the typing systems was satisfactory for all parameters tested. The phage sets that demonstrated the highest percentage of typability could not discriminate between epidemiologically related and unrelated strains. Reproducibility was likewise a problem. No agreement could be reached as to a standard phage-typing set or a standardized typing method. The suggestion by Parisi et al. (115) that there might be geographic variation in phage sensitivity among isolates of coagulase-negative staphylococci makes the problem of standardization even more complex.

Despite these problems, phage typing has been used successfully to type coagulase-negative staphylococci, particularly in epidemic situations $(100,106,113,114,158)$. Christensen et al. (26) demonstrated that phage typing alone was a poor strain discriminator (assignment probability $\boldsymbol{P}=$ 0.356 ) in a nonepidemic situation, but when combined with the antibiogram and biotyping it provided adequate discrimination between strains (assignment probability $P=0.015$ ). They suggested that possibly phage typing of coagulasenegative staphylococci is better reserved for epidemic rather than endemic situations.

Molecular typing. The application of molecular typing, including plasmid pattern analysis, restriction endonuclease analysis of plasmid and chromosomal DNA, and DNA hybridization, is proving to be a promising means of identifying strains or a clonal population of staphylococci $(6,41$, $66,106,111,112,114,130,161)$. Plasmid analysis is now available in a number of clinical microbiology laboratories and provides a rapid method of characterizing bacterial isolates. Several features of plasmid analysis make it especially appealing in the study of coagulase-negative staphylococci. (i) The ease with which plasmids can be detected by gel electrophoresis from crude bacterial lysates puts plasmid analysis well within the capabilities of many clinical laboratories $(6,16,66,105,106,161)$. (ii) A high percentage of coagulase-negative staphylococci ( $90 \%$ of S. epidermidis) have at least one and frequently multiple plasmids. Therefore, each strain produces a characteristic profile made up of its distinct plasmids $(6,106,113,114)$. Comparison of these profiles from different isolates from the same patient or from different patients in an endemic or epidemic situation will help define the epidemiology of coagulase-negative staphylococcal infections. (iii) Further identification of individual plasmids can be achieved by restriction endonuclease treatment of the plasmids followed by gel electrophoresis. Two plasmids of identical sizes can be judged to be identical or different based on their restriction fragment patterns $(66$, $111,112,161$ ). (iv) Plasmid analysis has been shown to be a useful tool in evaluating a number of clinical situations including septicemias $(6,113)$, differentiating contaminants from organisms responsible for prosthetic valve endocarditis, intravenous catheter sepsis, urinary tract infections, and osteomyelitis $(66,106,111,112,114,161)$. (v) Studies of coagulase-negative staphylococci, $S$. aureus, and Enterocaccus faecalis demonstrate transfer of antibiotic resistance plasmids among these organisms $(5,47,48,78,130,131$, 153). The studies suggest that, in addition to being a significant pathogen, multiply resistant coagulase-negative staphylococci may be a reservoir of resistance for other organisms.

Plasmid profiles were first used to distinguish different strains of coagulase-negative staphylococci by Parisi and 
Hecht (113), who were able to demonstrate the existence of a common strain of $S$. epidermidis causing infection among infants in a neonatal unit. These findings suggested that the infective strain was being passed from infant to infant. Subsequently, Archer and co-workers (6) have demonstrated the great diversity of plasmid patterns, and therefore strains of $S$. epidermidis, among isolates from different patients, from the same site on a given patient at different sampling times, and from different sites on a given patient at the same sampling time. Similar to previous studies, which demonstrated that surgery and antibiotic prophylaxis promoted colonization with antibiotic-resistant strains of coagulase-negative staphylococci $(4,7)$, they showed that skin cultures taken after surgery yielded isolates with plasmid patterns different from those taken before surgery.

Despite the many advantages of plasmid pattern analysis, the use of this technique to determine whether two isolates of coagulase-negative staphylococci are identical is not without shortcomings $(6,66,106,111,112,114)$. (i) Technical factors such as variations in the plasmid extraction methods which may convert one molecular form of the plasmid to another or in the conditions of electrophoresis can all influence the final profile $(6,66,106,111)$. (ii) Strains may lose antibiotic resistance plasmids or cryptic plasmids $(106,111,112)$. (iii) The ability to distinguish between two isolates decreases directly with the number of bands present and the diminishing difference in molecular size between two bands $(6,111)$. (iv) Conjugal transfer of plasmids within or between species of staphylococci can lead to differences in plasmid patterns $(5,47,58,78,130,131,153)$. Mickelsen et al. (106) observed that epidemiologically related strains of $S$. epidermidis may differ by as many as three plasmids. They found that, despite the lack of complete identity of all isolates, a conserved core of several plasmids of identical molecular weight enabled them to recognize the relatedness of isolates from the same as well as from different patients. They suggested that additional experience is needed with isolates that are well defined epidemiologically, phenotypically, and genotypically to define the limitations of plasmid pattern analysis as an epidemiological tool. Likewise, Parisi et al. (114) noted occasional minor differences in plasmid pattern among isolates of $S$. epidermidis which were otherwise identical by phenotypical and epidemiological criteria. They suggest that, although plasmid pattern analysis is a very powerful epidemiological tool, a combination of methods (specifically, plasmid profiling plus phage typing) may provide the most useful epidemiologic data.

The techniques of restriction endonuclease analysis and DNA hybridization provide additional information on the nucleotide sequence within the plasmid and make it possible to confirm the identity between plasmids with a high degree of confidence. Restriction endonucleases are enzymes that recognize specific, palindromic base sequences and cleave those sequences at a defined position. No two different plasmids should have the identical restriction sites at identical intervals along the plasmid DNA. Thus, two plasmids with identical products or "fingerprints" after digestion with these enzymes are likely to be identical. Cutting plasmids with these enzymes adds about an hour to the plasmid isolation procedure and does not significantly affect the cost. Restriction endonuclease analysis can be used to type organisms not containing plasmids. Chromosomal DNA can also be digested by restriction endonucleases, resulting in unique reproducible electrophoretic gel patterns $(66,161)$. Although its use has not been established for coagulase-negative staphylococci, several different microorganisms have been successfully typed with this technique (161). Finally, although quite different from plasmid pattern analysis or DNA restriction analysis, DNA hybridization techniques are also based on the unique physical properties of DNA $(99,112$, $149,161)$. By taking advantage of the fidelity of base pairings, one can unequivocally establish that two plasmids are identical by using a DNA fragment or an entire plasmid from one of the strains as a labeled probe in a Southern hybridization assay (149). This technique has been used by Parisi (112) to confirm the transmission of a strain of $S$. epidermidis from a surgeon to two patients following coronary artery bypass surgery. Although primarily a research tool, this technique may see increasing application in epidemiologic studies due to its power and flexibility.

Slime production. Slime production by coagulase-negative staphylococci has been associated with the ability of these organisms to adhere to the surfaces of catheters and other plastic biomedical devices $(27-29,62,118,120,143)$. Although of primary interest in the pathogenesis of coagulasenegative staphylococcal infections (see below), this property has also been found by several investigators to be an efficient discriminator between infective and noninfective strains of $S$. epidermidis $(9,25,29,35,38,76,168)$. Recent evidence suggests that phenotypic variation in slime production may occur in some strains of $S$. epidermidis (24); however, the extent and significance of this variability is unclear, and slime production is generally considered to be a stable phenotypic trait $(26,27,35,38,76)$. Christensen et al. $(26$, 27) described a test for slime production which, although nonstandardized, has been used by several investigators to study the clinical significance of slime-positive and slimenegative coagulase-negative staphylococci $(35,38,40,76$, $93,108)$. The slime test is performed by inoculating a loopful of organisms from the surface of a blood agar plate into a polystyrene tube containing 5 to $10 \mathrm{ml}$ of tryptic soy broth and incubating at 35 to $37^{\circ} \mathrm{C}$ for 24 to $48 \mathrm{~h}$. The contents of the tubes are then aspirated, washed with distilled water, and stained with either alcian blue or safranin. Slime production is judged to have occurred if a visible film lines the wall of the tube. Formation of a ring at the liquid-air interface is not considered indicative of slime production. Very little comparative data exist describing the effects of variation in the test procedure on slime production. Christensen et al. (27) reported that slime production in vitro requires both glucose and casein digests for expression. They found that many commonly used laboratory media such as brain heart infusion, Todd-Hewitt, brucella, MuellerHinton, nutrient, tryptone, and sucrose broths do not support slime production. Although there does not appear to be a significant difference between polystyrene and glass, polypropylene is not optimal as a substrate for the demonstration of the slime layer on the walls of the tubes $(27,29)$.

The reproducibility of the slime test has been analyzed in three independent studies $(29,35,38)$. Davenport et al. (35) and Diaz-Mitoma et al. (38) both found the intra-assay, interassay, and interobserver reproducibilities of the slime test to be excellent, ranging form 90 to $100 \%$ (kappa $=0.9$ to 1.0; $P<0.001$ ). In contrast, Christensen et al. (29) noted variability between observers in interpreting tests of weakly positive strains of coagulase-negative staphylococci. This may be accounted for by the subjective and qualitative nature of the test, an obvious limitation. Quantitative assays for both slime production and adherence of coagulasenegative staphylococci to plastic have been developed to provide a more objective means to assess this important phenotypic characteristic $(29,121 a)$. These tests will facili- 
tate comparison of slime production by different strains and species of these organisms and perhaps will serve as the basis for development of a more standardized assay for slime production.

The clinical and epidemiological usefulness of the slime test was first described by Christensen and co-workers (2529). These investigators demonstrated that, when used in combination with the antibiogram and the API Staph-Ident, slime production had a very high discriminatory power for delineating individual strains of $S$. epidermidis (26). They also found that the frequency of slime production was significantly higher $(63 \%)$ in strains associated with clinical signs of intravascular catheter-associated sepsis than in strains not associated with signs of infection (37\%) (27). These findings suggested that testing isolates for slime production, either alone or in combination with other phenotypic markers, may provide a simple method of distinguishing true pathogens from clinically insignificant isolates of coagulase-negative staphylococci. These studies were potentially limited by the fact that the isolates of coagulasenegative staphylococci were collected during an epidemic of catheter-related sepsis $(25,27)$. Thus, the relationship between slime production and infection may merely represent the characteristics of the epidemic strain rather than a unique characteristic of pathogenic coagulase-negative staphylococci.

The initial observations of Christensen et al. $(26,27)$ have subsequently been validated by several studies supporting the relationship between slime production and infection in nonepidemic, as well as epidemic, situations $(35,40,76$, 168). Davenport et al. (35) demonstrated that, in patients with prosthetic devices, repeated isolation of a slime-positive coagulase-negative staphylococcus was four times more likely to represent clinically significant disease than contamination. Dunne et al. (40) and Younger et al. (168) independently documented a significant association between slime production and clinical infection in pediatric patients. Ishak et al. (76) found that, whereas the isolation of $S$. epidermidis from blood gave a positive predictive value for clinical infection of $67 \%$, the determination that the isolate was also slime positive increased the positive predictive value to $87 \%$. These results suggest that knowledge of the species of coagulase-negative staphylococci and its ability to produce slime may aid the clinician and clinical microbiologist in evaluating the clinical significance of such an isolate growing from a blood culture.

Despite the enthusiasm of the previously mentioned authors for slime production as a marker of infection, other investigators have found that slime production is not a universal feature of those strains causing infection $(38,93$, 108). Needham and Stempsey (108), Kristinsson et al. (95), and Diaz-Mitoma et al. (38) have all failed to demonstrate a significant difference in slime production between infective and noninfective strains of coagulase-negative staphylococci. These findings indicate that slime-negative strains of coagulase-negative staphylococci can cause infection and that slime-positive strains also may be colonizing rather than infecting strains. The reasons for the differences between the various clinical studies is not readily apparent at the present time. Subtle differences in the methods used to detect slime production in vitro may have profound effects on the results of the slime assay and thus affect the clinical relevance of in vitro slime production in the various studies $(27,29)$. Clarification of the role of the test for slime production in medical decision making will require additional clinical and epidemi- ological studies and will be facilitated by the development of standardized test methods.

\section{Antimicrobial Resistance and In Vitro Susceptibility Testing}

The susceptibility of coagulase-negative staphylococci to antimicrobial agents is extremely variable. Although community-acquired isolates are frequently susceptible to a wide variety of agents, strains isolated from hospitalized patients have been noted to be resistant to an increasing number of antibiotics $(3,4,7,25,34,50,63,73,82,122,124,136,146)$. In particular, a marked increase in the resistance of $S$. epidermidis to gentamicin, erythromycin, chloramphenicol, and methicillin has been reported $(3,4,25,63,82)$. Karchmer et al. (82) reported that $83 \%$ of $S$. epidermidis isolates from their patients with prosthetic valve endocarditis were methicillin resistant, and Archer (3) found that $67 \%$ of clinical isolates obtained from blood, cerebrospinal fluid, or heart valve tissue were resistant to six or more antibiotics. Recently, Galetto et al. (52) reported that $17 \%$ of 101 isolates of $S$. epidermidis collected from the Medical College of Virginia and other geographic locations prior to 1982 were resistant to trimethoprim versus $43 \%$ of 102 isolates collected from the Medical College of Virginia in 1986. Using a probe for the trimethoprim resistance gene of $S$. aureus (pG018), they demonstrated that the genetic determinant responsible for this resistance was found on a large, conjugative, multiresistance plasmid in both $S$. aureus and $S$. epidermidis as well as in both chromosomal DNA and small nonconjugative plasmids in $S$. epidermidis. Similarly, Archer et al. (5) and others $(47,78,130,131,153)$ have demonstrated conjugative transfer of gentamicin resistance plasmids from coagulase-negative staphylococci to coagulase-negative staphylococci and from coagulase-negative staphylococci to $S$. aureus. These data suggest that coagulase-negative staphylococci, particularly $S$. epidermidis, may be a reservoir for antibiotic resistance genes in the hospital environment. Future studies with DNA probes for antibiotic resistance genes of coagulase-negative staphylococci should help clarify this issue and provide a rational approach to control and spread of these resistance factors among hospital pathogens.

Several pitfalls in the performance of antimicrobial susceptibility testing of coagulase-negative staphylococci should be recognized and avoided. Resistance to penicillin is very common, particularly among hospital strains of coagulase-negative staphylococci, and is frequently mediated by a beta-lactamase-producing plasmid $(3,58)$. Beta-lactamasemediated resistance to penicillin is frequently not detected by routine microdilution methods, and all isolates which appear susceptible to penicillin or ampicillin should be tested for beta-lactamase production (58). The beta-lactamase enzyme in staphylococci is inducible and may not be fully expressed in all isolates; therefore, to avoid false-negative results, isolates must be exposed to an appropriate inducing agent, such as oxacillin, prior to beta-lactamase testing (58, 140). Selepak and Witebsky (138) demonstrated that up to $60 \%$ of clinical isolates of coagulase-negative staphylococci would be misclassified as beta-lactamase negative if betalactamase testing were performed without prior induction. They recommend that the beta-lactamase tests be performed with induced organisms taken from the edge of the zone of inhibition around a $1-\mu \mathrm{g}$ oxacillin disk $(58,138)$.

In contrast to penicillin resistance, resistance of staphylococci to methicillin and other penicillinase-resistant penicil- 
lins (PRP) such as oxacillin and nafcillin is not mediated by beta-lactamase production, but rather is thought to be due, in part, to an altered penicillin-binding protein (PBP 2a or PBP 2') $(22,104,157)$. The association between PBP 2a (PBP $2^{\prime}$ ) and resistance to the PRPs has been well established for $S$. aureus but until recently has not been clearly demonstrated for coagulase-negative staphylococci $(22,157)$. The recent report of Chambers (22) convincingly demonstrates that methicillin resistance in coagulase-negative staphylococci and therapeutic failure with beta-lactam antibiotics in vivo are associated with the production of an altered PBP, PBP 2a, which is antibiotic inducible, has a low binding affinity for beta-lactam antibiotics, and is identical to PBP $2 a$ (PBP 2') found in methicillin-resistant $S$. aureus.

Detection of coagulase-negative staphylococci which are resistant to the PRPs is a major problem because PRPresistant isolates are phenotypically heteroresistant to methicillin and the other PRPs $(3,65,82$; C. Thornsberry, Antimicrobic Newsl. 1:43-47, 1984). This means that, although each organism in a population may have the genetic information necessary for PRP resistance, only a small fraction $\left(10^{-6}\right.$ to $\left.10^{-4}\right)$ can actually express the PRP-resistant phenotype under in vitro testing conditions and thus may be easily missed when in vitro susceptibility testing is performed $(3,65,82,103,104,156$; Thornsberry, Antimicrobic Newsl. 1:43-47, 1984). In vitro expression of the PRPresistant phenotype is favored by the presence of 2 to $5 \%$ $\mathrm{NaCl}$ in the medium, incubation temperatures of 30 to $35^{\circ} \mathrm{C}$ and growth on agar rather than in broth medium $(31,50,65$; Thornsberry, Antimicrobic Newsl. 1:43-47, 1984). It appears, based on recent studies with $S$. aureus, that production of the altered PBP (PBP 2a or PBP $2^{\prime}$ ) is stimulated at lower incubation temperatures $\left(30\right.$ to $\left.32^{\circ} \mathrm{C}\right)$ and by $\mathrm{NaCl}(22$, $96,157)$; however, this has not been documented independently in coagulase-negative staphylococci. Thus, the expression of resistance as detected by in vitro testing methods is influenced by several factors, including inoculum size and preparation, time and temperature of incubation, and medium composition and osmolality $(3,31,50,65,82$, 103, 104, 156; Thornsberry, Antimicrobic Newsl. 1:43-47, 1984). Although there is a reasonable correlation between the effects of these various environmental factors on PBP $2 a$ (PBP 2') production and expression of PRP resistance in staphylococci, it is likely that PBP 2a (PBP 2') production alone is not the entire explanation for PRP resistance (96, 157). Regardless of the mechanism of PRP resistance, it is important to realize that routine susceptibility testing with methicillin, oxacillin, or nafcillin disks, automated turbidimetric systems, and microdilution systems may all yield false-susceptible results.

Several recommended modifications of the standard disk diffusion and broth dilution susceptibility methods improve detection of PRP-resistant strains of staphylococci (31, 50, 65, 103, 104, 156; Thornsberry, Antimicrobic Newsl. 1:43$47,1984)$. Although initially optimized for the detection of PRP-resistant $S$. aureus, these methods have generally been shown to improve the detection of PRP-resistant coagulasenegative staphylococci $(31,50,156,167)$. The current recommendations for optimal detection of PRP resistance are as follows. (i) The inoculum should be prepared by suspending organisms taken directly from an overnight (18- to 24-h) growth on an agar plate to the turbidity of a $0.5 \mathrm{McF}$ arland standard (direct inoculum preparation). (ii) The inoculum size should be $10^{8}$ colony-forming units per ml for disk diffusion testing and $5 \times 10^{5}$ colony-forming units per ml for broth dilution testing. Lower inocula may result in false- susceptible results. (iii) The medium used for broth dilution testing should be cation-supplemented Mueller-Hinton broth which has been further supplemented with $\mathrm{NaCl}(2 \%$ final concentration) in the PRP-containing wells only. (iv) All tests should be incubated at $\leq 35^{\circ} \mathrm{C}$ for $24 \mathrm{~h}$. Higher temperatures or shorter incubation times may result in the failure to detect PRP resistance. (v) When performing disk diffusion testing, one should use either oxacillin- or methicillin-containing disks rather than nafcillin-, cloxacillin-, or dicloxacillin-containing disks. (vi) Using transmitted light, examine the zone of inhibition surrounding the oxacillin or methicillin disk for the presence of small colonies or a haze of growth indicating the presence of a resistant subpopulation. The use of a larger inoculum or prolonged incubation or both has been suggested by some investigators $(31,50,167)$; however, it is not generally recommended and may result in falseresistant or intermediate results in some strains (104; Thornsberry, Antimicrobic Newsl. 1:43-47, 1984). Additional clues to the presence of PRP-resistant staphylococci are resistance to multiple antibiotics including erythromycin, clindamycin, tetracycline, chloramphenicol, and gentamicin, an intermediate result to methicillin or oxacillin, and resistance to one but not all PRPs.

The recent reports of Coudron et al. (31) and Woods et al. (167) support most of the recommendations discussed above and offer additional recommendations specific for coagulasenegative staphylococci. Coudron et al. (31) reported that (i) prolonged incubation ( $>24 \mathrm{~h}$ ) was usually not necessary to detect methicillin-resistant coagulase-negative staphylococci, (ii) methicillin was better than oxacillin for detecting methicillin-resistant $S$. epidermidis, and (iii) reliable alternative procedures for detecting methicillin-resistant coagulasenegative staphylococci include the spread plate and spot methods, using Mueller-Hinton agar supplemented with $4 \%$ $\mathrm{NaCl}$ and either methicillin $(10 \mu \mathrm{g} / \mathrm{ml})$ or oxacillin $(6 \mu \mathrm{g} / \mathrm{ml})$, and also the conventional disk diffusion method if salt (4\% $\mathrm{NaCl}$ ) is added to the medium and plates are read at $18 \mathrm{~h}$. Woods et al. (167) recommend the use of a direct inoculum and either (i) a $24-\mathrm{h}$ disk diffusion test with oxacillin $(1 \mu \mathrm{g} / \mathrm{ml})$ incubated at $35^{\circ} \mathrm{C}$ or (ii) an oxacillin agar screen (MuellerHinton agar supplemented with $4 \% \mathrm{NaCl}$ and $6 \mu \mathrm{g}$ of oxacillin per $\mathrm{ml}$ ) incubated at $35^{\circ} \mathrm{C}$ for $24 \mathrm{~h}$. In contrast to the above recommendations, they found prolonged (48-h) incubation useful when intermediate results were obtained at 24 $h$ and did not find $\mathrm{NaCl}$ supplementation or direct inoculum preparation useful when broth dilution testing was performed. It should be noted that, in general, the above recommendations deal primarily with increasing the sensitivity of in vitro tests for detection of heteroresistant staphylococci. Determination of the specificity and clinical relevance of the increased detection require further clinical and laboratory investigation.

An additional confusing issue is the question of crossresistance between cephalosporins and the PRPs. Routine susceptibility testing will frequently show PRP-resistant $S$. epidermidis to be susceptible to cephalosporins, including broad-spectrum cephalosporins, when, in fact, cross-resistance is extensive $(3,50,65,82,103,104,156$; Thornsberry, Antimicrobic Newsl. 1:43-47, 1984). The recent report of Chambers (22) linking the presence of PBP 2a in coagulasenegative staphylococci with therapeutic failure of betalactam antibiotics of the penicillin, cephalosporin, and penem classes is evidence that these strains (containing PBP 2a) are cross-resistant to all beta-lactam antibiotics, regardless of in vitro susceptibility. Thus, for clinical purposes, all PRP-resistant staphylococci should be reported as resistant 
to all beta-lactam agents regardless of their in vitro susceptibility $(3,22,50,65,82$; Thornsberry, Antimicrobic Newsl. 1:43-47, 1984).

Due to the increasing frequency of PRP resistance among coagulase-negative staphylococci, vancomycin has become the antibiotic of choice for nosocomial infections caused by these organisms $(64,82,83,95$; Dunne and Franson, Clin. Microbiol. Newsl. 8:37-42, 1986). Resistance to vancomycin is rare; however, Schwalbe et al. (136) have recently reported the in vivo development of resistance to vancomycin by a strain of $S$. haemolyticus. These investigators were also able to select for vancomycin resistance in vitro and have found changes in the cell wall associated with the resistant clones, suggesting decreased antibiotic uptake as a mechanism for vancomycin resistance (137). Despite these findings, there is currently no clinical or laboratory evidence suggesting the spread or potential for spread of vancomycin resistance among coagulase-negative staphylococci. Vancomycin susceptibility testing of coagulase-negative staphylococci is reliable and is predictive of in vivo response. In vitro studies done with combinations of vancomycin and other antistaphylococcal agents such as gentamicin, tobramycin, or rifampin have demonstrated synergy against clinical isolates of coagulase-negative staphylococci, and such combinations have been useful in the treatment of serious infections due to these organisms $(82,136)$.

\section{EPIDEMIOLOGY AND CLINICAL SIGNIFICANCE}

Because of their prevalence on the skin and frequent implantation of foreign devices into patients during hospitalization, coagulase-negative staphylococci are ideally situated to cause serious infection in these patients. Infections due to coagulase-negative staphylococci have several common features. They are usually nosocomial in origin $(25,34$, $50,64,67,95,107,123,129,151,162,165,166$; Dunne and Franson, Clin. Microbiol. Newsl. 8:37-42, 1986), involve $S$. epidermidis as the most common etiologic agent $(25,26,42$, $64,76,77,107,112,123,151$ ), and are associated with implanted prosthetic devices such as intravenous catheters, prosthetic heart valves, prosthetic joints, or central nervous system shunts $(3,8,9,19,20,23,30,62,75,81,82,97,120$, $129,141,154)$. Colonization of foreign bodies by coagulasenegative staphylococci frequently leads to serious local and systemic disease. Bacteremia, endocarditis, mediastinitis, meningitis, and progressive joint destruction are all wellrecognized complications of prosthetic device infections due to coagulase-negative staphylococci $(8,18,25,30,34,38,48$, $50,64,67,75,81,82,84)$.

Contrary to popular opinion, serious infection caused by coagulase-negative staphylococci is not a new phenomenon, although the incidence of such infections has clearly increased in recent years $(25,49,151,162,166)$. In a review published in 1958, Smith et al. (148) described a total of 90 cases of coagulase-negative staphylococcal septicemia reported in the literature between 1900 and 1955. In addition, they reported that $1.5 \%$ of staphylococcal bacteremias at the University of Iowa form 1936 and 1955 were caused by coagulase-negative staphylococci. The majority of these patients had "predisposing factors," the most common of which was previous rheumatic fever. Subsequently, Smith (147) reported an increase in the rate of coagulase-negative staphylococcal septicemia at the University of Iowa from 0.5 cases per 10,000 admissions in 1945 to 1955 to 1.3 cases per 10,000 admissions in 1974 to 1978 . During the latter period, $69 \%$ of the infections were associated with the presence of a foreign body and $59 \%$ were postoperative. More recently, Martin et al. (M. A. Martin, T. M. Perl, M. A. Pfaller, and R. P. Wenzel, Program Abstr. 27th Intersci. Conf. Antimicrob. Agents Chemother. abstr. no. 1300, 1987) completed a 7-year surveillance study at the University of Iowa which supports the earlier hypothesis of Smith (147) that the incidence of coagulase-negative staphylococcal septicemia was increasing. They found that from 1980 to 1987 it increased from 8 to $26 \%$ of all nosocomial bloodstream infections, and the infection rate increased from 5.2 to 38.6 cases per 10,000 admissions.

The findings reported from the University of Iowa are supported by data from many other institutions $(25,49,151$, $162,166)$. Stillman et al. (151) reported an increase in the rate of coagulase-negative staphylococcal nosocomial bloodstream infections at the University of Virginia from 5.2 per 10,000 admissions during 1975 to 1978 to 12.4 per 10,000 admissions during 1979 to 1982 . Sixty-four percent of all coagulase-negative staphylococcal bloodstream infections were found in critical-care areas. Winston et al. (166), in a study of 130 immunocompromised patients, reported an increase in the yearly incidence of coagulase-negative staphylococci from $15 \%$ of all bacteremias in 1977 to $33 \%$ of all bacteremias in 1980. Coagulase-negative staphylococci were the most common cause of all bacteremias during this time period. Wade et al. (162) reported that, in their cancer patients with granulocytopenia, the rate of coagulase-negative staphylococcal infections increased from 2.0 per 1,000 patient-days of hospitalization prior to 1977 to 14.6 per 1,000 days in 1979.

A recent study by Freeman et al. (49) raises a note of caution concerning the many reports of the increasing incidence of coagulase-negative staphylococcal bacteremia. They noted a fivefold increase in the number of cases of nosocomial coagulase-negative staphylococcal bacteremia in their neonatal intensive care unit from 1975 to 1982 . They concluded that this represented neither an increase in the frequency of isolation of coagulase-positive staphylococci nor an increase in the frequency of obtaining blood cultures. Rather, they attributed it to a $62.3 \%$ increase in the neonatal intensive care unit bed use by infants with birth weights of $<1,000$ g. Positive blood cultures were 3.8 times more likely to be considered clinically significant in these infants than in those with higher birth weights. This study emphasizes the need for controlled studies evaluating both the incidence of and risk factors for coagulase-negative staphylococcal infections in hospitalized patients.

Although coagulase-negative staphylococci are generally considered to be of low virulence, the reported crude mortality rates associated with coagulase-negative staphylococcal bacteremia are quite high, ranging from 27 to $78 \%(25$, 48, 123, 129, 147, 151; Dunne and Franson, Clin. Microbiol. Newsl. 8:37-42, 1986). Because many of these patients have serious underlying diseases, it is important to distinguish the mortality actually attributable to the nosocomial coagulasenegative staphylococcal bacteremia from that due to the underlying disease. Martin et al. (27th ICAAC) recently reported the results of a retrospective matched case control study in which the crude mortality in a group of 58 patients with coagulase-negative staphylococcal nosocomial bloodstream infection and their controls was 31 and $19 \%$, respectively. In an effort to control for confounding variables such as severity of underlying diseases and other comorbid factors, the patients and controls were closely matched for age, sex, type and severity of underlying disease, and surgical procedures. One hundred percent of the patients and their 
controls were matched for primary diagnosis, and $89 \%$ were matched for secondary diagnosis. To ensure that the control's duration of exposure to risk factors for coagulasenegative staphylococcal bacteremia was at least as long as that of the patient, controls were considered only if their total length of stay was greater than or equal to the time from admission to infection for the patient. The morality directly attributable to coagulase-negative staphylococcal bloodstream infection in this study was $12 \%$. In addition, the median length of hospital stay for the patients was 55 days compared with 41 days for controls, yielding an excess length of stay of 14 days directly attributable to the infection. Thus, the increase in mortality directly attributable to coagulase-negative staphylococcal nosocomial bloodstream infection was substantial, and the increase in length of stay imposes a significant economic burden.

While sepsis is the most common manifestation of coagulase-negative staphylococcal infection, gastrointestinal (162), pharyngeal $(162,166)$, urinary tract $(123,166)$, skin $(123,166)$, and pulmonary $(162,166)$ infections have been documented. One major problem in the prevention and diagnosis of coagulase-negative staphylococcal infections in hospitalized patients is the difficulty in differentiating infection from colonization. The clinical signs and symptoms associated with both local and systemic coagulase-negative staphylococcal infections are well known, but are not specific, and may be masked in critically ill patients. Furthermore, cultures obtained from a variety of body sites are frequently confusing or misleading due to the propensity of these organisms to colonize.

Attempts to identify the reservoirs and the site of origin of the strains of coagulase-negative staphylococci causing nosocomial infections have been hampered by the inadequacies of epidemiologic typing systems and by the presence of multiple strains on each individual $(23,41,111)$. It is generally believed that coagulase-negative staphylococci colonizing the skin of the individual patient are the usual source of coagulase-negative staphylococcal bacteremia and prosthetic device infection $(6,9,23,25,41,64,67,82$; Dunne and Franson, Clin. Microbiol. Newsl. 8:37-42, 1986). However, Wade et al. (162) and Khabbaz et al. (R. F. Khabbaz, R. C. Cooksey, G. Saba, and J. C. Wade, Program Abstr. 27th Intersci. Conf. Antimicrob. Agents Chemother., abstr. no. $1036,1987)$ have provided evidence to support the gastrointestinal tract as an important source for coagulase-negative staphylococcal bacteremia, and Parisi (112) has convincingly documented transmission of coagulase-negative staphylococci from hospital staff to patients. In addition, epidemiologic and microbiologic studies have suggested that coagulase-negative staphylococcal infections of cardiac or orthopedic prostheses may be initiated at the time of implantation with the flora of the patient, surgeon, or environmental isolates (48, 50, 73; Dunne and Franson, Clin. Microbiol. Newsl. 8:37-42, 1986). Despite these studies, there are major deficiencies in our understanding of important factors relating to infection with coagulase-negative staphylococci. Very little is known concerning the significance and length of carriage of $S$. epidermidis or other species of coagulasenegative staphylococci by patients and hospital staff. Likewise, the reservoir of the infecting strains and the mechanism of transmission of coagulase-negative staphylococci within the hospital are poorly understood. Although differences in species, antibiogram, biotype, and plasmid pattern of coagulase-negative staphylococci causing infection and merely colonizing patients have been noted, these differences have not been fully exploited to differentiate strains for epidemiologic purposes and have not been incorporated into a unified explanation of the pathogenicity of the organisms.

\section{PATHOGENESIS OF COAGULASE-NEGATIVE STAPHYLOCOCCAL INFECTIONS}

\section{Host Factors}

The emerging role of coagulase-negative staphylococci as important nosocomial pathogens has prompted increased interest in the pathogenesis of coagulase-negative staphylococcal infections. Host factors that often may lead to serious infections with coagulase-negative staphylococci are well characterized. These factors include breaches in natural mucocutaneous barriers due to trauma or inflammation (33, $50,67,73,80,83,97,102,162,166)$, prior exposure to antibiotics $(3,4,7,25,50,83,124,136)$, and immunosuppression $(19,46,75,83,121,160,162,166)$. Patients with cancer and granulocytopenia appear to be a particularly high-risk group presumably due to the combined presence of granulocytopenia and mucosal damage and concurrent colonization of the alimentary tract by coagulase-negative staphylococci $(75,83,162,166)$. Recent studies indicate that either systemic or localized opsonic deficiency may be a risk factor for coagulase-negative staphylococcal infection in neonates (46) and continuous ambulatory peritoneal dialysis patients $(19,85,121,160)$ respectively. In a study of continuous ambulatory peritoneal dialysis patients it was found that those with low opsonic activity in their peritoneal fluid had a 10-fold-greater incidence of peritonitis than those with a high opsonic activity $(19,85)$. In addition, reduced numbers of peritoneal macrophages and intraleukocytic sequestration of viable coagulase-negative staphylococci may also be important in clinical continuous ambulatory peritoneal dialysis peritonitis $(19,121,160)$.

Although host defects are clearly important in the pathogenesis of coagulase-negative staphylococci infections, perhaps the most important factor contributing to the increasing number of nosocomial coagulase-negative staphylococcal infections is the presence of indwelling prosthetic devices in both compromised and noncompromised hosts. Thus serious (septic) infections caused by coagulase-negative staphylococci are most commonly associated with indwelling intravenous catheters, cardiac valve prostheses, prosthetic orthopedic devices, cerebrospinal fluid shunts, ventriculostomy drains, peritoneal dialysis catheters, and transvenous cardiac pacemakers $(8,25-28,30,35,62,64,67,72,75,81$, $82,95,97,106,118-120,135,141,154,166,168$; Dunne and Franson, Clin. Microbiol. Newsl. 8:37-42, 1986). The mechanisms by which coagulase-negative staphylococci gain access to the surfaces of the various prosthetic devices currently is a matter of debate and intense investigation. The source of the contaminating organism may be endogenous from the skin or mucosal (pulmonary or alimentary tract) surfaces of the patient or exogenous from the hospital environment or the hands of hospital personnel $(4,17,25,34$, $40,50,73,94,97,154,162,166)$. At least four possible mechanisms have been postulated for the introduction of coagulase-negative staphylococci onto the surfaces of prosthetic devices and subsequently into the bloodstream or other normally sterile sites. (i) The microorganisms are introduced via the catheter tunnel and the exterior of the catheter $(17,23,50,97,166)$. (ii) The coagulase-negative staphylococci gain access to the catheter lumen following frequent catheter disconnections. The hub of the catheter 
becomes colonized with these organisms secondary to exposure to the skin of the patient and to the hands of health care personnel performing catheter care and thus serves as the reservoir for the contaminating organism $(23,50,94,97$, 154). (iii) The microorganisms are introduced during the percutaneous or surgical implantation of the catheter, shunt, or cardiac or orthopedic prosthesis $(20,33,50,82,97,102$, 141). (iv) The organisms transiently enter the bloodstream or other normally sterile site from an endogenous source (pulmonary or alimentary tract) and subsequently colonize the implanted foreign device $(20,30,50,83,97,162)$. Regardless of the mechanism, introduction of coagulase-negative staphylococci onto the surface of a prosthetic device may result in the formation of an adherent biofilm which then may serve as a persistent septic focus $(9,27,28,35,38,62,76,118-121$, $142,143,154,160,168)$. The presence of the foreign body may further compromise host defenses by creating a microenvironment which adversely affects opsonization and polymorphonuclear phagocytosis and bactericidal activity (19, $28,62,64,120,121,143,154,160,169)$.

Because infections caused by coagulase-negative staphylococci seldom occur in patients free of predisposing factors such as immunosuppression and prosthetic devices, these organisms are commonly thought of as avirulent, opportunistic organisms and not true pathogens $(42,59,64$, 95, 111, 139, 140, 154, 162; Dunne and Franson, Clin. Microbiol. Newsl. 8:37-42, 1986). Although the presence of a foreign body may facilitate infection by protecting the organism from elimination by host defense or antimicrobial therapy, it has become increasingly clear that some coagulase-negative staphylococci possess unique microbial factors which make them particularly adapted to survival on a variety of biomaterials $(8,27,29,62,69,116,118-120,142$, 143, 154; Dunne and Franson, Clin. Microbiol. Newsl. 8:37$42,1986)$. In addition, recent data suggest that coagulasenegative staphylococci, particularly $S$. epidermidis, possess several virulence factors common to $S$. aureus and may be intrinsically more virulent than previously thought $(53,55$, $56,98,163)$.

\section{Microbial Factors}

Recent investigations into the pathogenesis of coagulasenegative staphylococcal infections suggest that once these organisms overcome the normal cutaneous or mucocutaneous protective barriers, they adhere to and proliferate on certain biosynthetic materials (catheters, etc.) and cause local or systemic infection. The process of adherence, colonization, and infection exist in a sequential relationship (62). The ability of coagulase-negative staphylococci to adhere to and colonize the smooth surfaces of prosthetic devices appears to be directly related to virulence $(25-29,35,38,76$, 118-121, 168; Dunne and Franson, Clin. Microbiol. Newsl. 8:37-42, 1986). The mechanics of adherence of these organisms to prosthetic devices involves nonspecific electrostatic and hydrophobic interactions in the initial attachment stages $(29,62,69-71,116,118-121,143,159$; Dunne and Franson, Clin. Microbiol. Newsl. 8:37-42, 1986). Hogt et al. (69-71) and Reifsteck et al. (128) have demonstrated that the cell surfaces of clinical isolates of coagulase-negative staphylococci are frequently hydrophobic in nature. Many medical devices, such as catheters, prosthetic heart valves, and artificial organs, are manufactured from biopolymers which are highly hydrophobic. Polymers of high hydrophobicity are adhesive for many bacterial pathogens $(62,69-71,86$, $116,159)$, and Hogt et al. (69-71) have shown that strains of coagulase-negative staphylococci colonize these materials by hydrophobic binding. These findings have been extended by Pascual et al. (116), who demonstrated a direct linear relationship between the degree of hydrophobicity of the coagulase-negative staphylococci and adherence to Teflon and polyurethane catheters.

The initial rapid phase of hydrophobic attachment may be modulated by the interaction of organism and substrate with specific host proteins. Subsequent to or concomitant with initial attachment, specific adhesins and substratum receptors may interact if they are present in the particular biological system $(62,163)$. Recent studies indicate that clinical isolates of coagulase-negative staphylococci bind fibronectin, collagen, and possibly other host proteins which form part of the glycoproteinaceous conditioning films that immediately coat prosthetic implants $(62,163)$. Once attached to the surface of the implant a viscous extracellular polysaccharide substance or slime is produced which ultimately covers the bacteria completely, forming a biofilm on the surface of the implant $(27,62,118-121,154,163,168$; Dunne and Franson, Clin. Microbiol. Newsl. 8:37-42, 1986). The exopolysaccharide slime of coagulase-negative staphylococci is not a true capsule but rather a loosely adherent amorphous material consisting of glucose, galactose, mannose, glycerol, hexosamine, phosphorous, glycine, alanine, and phenylalanine $(62,121)$. The chemical composition may vary within and between species and may depend on the nutritional qualities of the environment. The slime material may function as an additional adhesin binding to the surface of the implant and further consolidating adhesion, aggregation, and microcolony formation $(62,118-121)$.

The biofilm produced by the staphylococcal slime matrix on the surface of a prosthetic device provides a protective microenvironment within which optimal growth conditions are created and from which antagonistic environmental factors are excluded $(62,118-121,142)$. The exopolysaccharide slime substance is believed to act as an ion-exchange resin for enhanced nutrition (62) and as a mechanical barrier to antibiotics $(62,121,142)$ and host defenses $(28,38,62,64$, 67, 118-121, 154; Dunne and Franson, Clin. Microbiol. Newsl. 8:37-42, 1986). In addition to serving as a mechanical barrier, slime may interfere biochemically with coagulation (21), neutrophil chemotaxis, and bactericidal activity (79, 109), and other aspects of the cellular immune system (61, 121).

In vitro studies have demonstrated enhanced adherence of slime-positive isolates of coagulase-negative staphylococci to catheters and have suggested that these strains may be uniquely adapted to adhere to smooth surfaces $(27,29,62$, 69, 116, 118-121, 142, 143, 154; Dunne and Franson, Clin. Microbiol. Newsl. 8:37-42, 1986). Slime-positive strains grow in vitro as a multilayered biofilm on the surface of intravascular catheters, whereas slime-negative strains do not $(27,118-121,142)$. Transmission and scanning electron micrographs of intravascular catheters and endocardial pacemaker wires taken from patients with $S$. epidermidis sepsis document the formation of staphylococcal biofilms in vivo and provide evidence for the clinical importance of slime production by coagulase-negative staphylococci $(120$, 121).

Recent animal studies have also suggested that slimepositive strains of $S$. epidermidis exhibit greater virulence in the presence of a foreign body (28). Confirmation of the importance of slime production for human infections has been derived from several recent clinical studies $(9,25,35$, $38,76,168)$. The studies of Christensen et al. (25-27, 29), 
Dunne et al. (40), Ishak et al. (76), and Davenport et al. (35) all demonstrate a significant association between the ability of an isolate to produce slime and its propensity to cause disease in patients with prosthetic devices. In addition, studies in our laboratory indicate that eradication of infection is more difficult when a slime-positive organism is involved (35). The recent reports of Younger et al. (168), Kristinsson et al. (93), and Diaz-Mitoma et al. (38) provide additional evidence in support of the association between the ability of the infecting isolate to produce slime and bacteriologic treatment failure. The test for slime production employed in these studies may be a useful tool for managing patients with prosthetic device-related infections due to coagulase-negative staphylococci, to indicate whether antimicrobial therapy alone or in combination with prosthetic device removal is necessary $(35,38,93,168)$. The data accumulated strongly suggest that slime production is an important factor in the colonization and infection of prosthetic devices; however, it is likely that slime production is only one of a number of important factors relating to the virulence of coagulase-negative staphylococci. The recent description of phenotypic variation in slime production by $S$. epidermidis (24) introduces an additional degree of complexity which must be addressed in future studies attempting to link slime production to pathogenesis.

Aside from the studies of the adherence properties of coagulase-negative staphylococci described above, little attention has been paid to other potential virulence factors of these organisms. Gemmell and co-workers $(53,55,56)$ have evaluated the exoproteins of coagulase-negative staphylococci and their possible pathogenicity in infections of humans and animals. They found that coagulase-negative staphylococci produced a wide variety of potential toxins including hemolysins, cytotoxins, deoxyribonuclease, fibrinolysin, proteinase, and lipase-esterase $(53,55,56)$. Strong similarities were noted between the exoproteins produced by $S$. aureus, $S$. epidermidis, $S$. haemolyticus, and $S$. saprophyticus, suggesting that these exoproteins may be important virulence factors in infections of humans.

Although not generally considered a virulence factor, resistance to multiple antimicrobial agents clearly plays a role in the pathogenesis of nosocomial coagulase-negative staphylococcal infections. As mentioned previously, the majority of hospital strains of coagulase-negative staphylococci are resistant to multiple antibiotics. Organisms that resist conventional prophylactic therapy given for implant surgery may play a role in establishing infection. Coagulasenegative staphylococci have been shown to develop resistance rapidly to a wide variety of antibiotics and may serve as a reservoir for antibiotic resistance genes $(3,4,5,7,47$, $52,78,130,131,153)$. Antimicrobial usage practices may select for multiresistant coagulase-negative staphylococci which colonize patients and staff who then serve as a hospital reservoir for antibiotic-resistant coagulase-negative staphylococci $(3,4,7,25,63,131,153)$.

\section{THERAPY}

The treatment of coagulase-negative staphylococcal infection is dependent on the severity and anatomic site of infection, the presence of a foreign body or prosthetic device, and the results of antimicrobial susceptibility testing. In general, if a foreign body is present, it must be removed to cure the infection $(35,38,64,82,95,119,120,168$; Dunne and Franson, Clin. Microbiol. Newsl. 8:37-42, 1986). A combined medical-surgical approach frequently is indicated to remove the infected device or to obtain adequate drainage of a sequestered site $(95,120)$. The choice of appropriate antimicrobial therapy is complicated by the difficulties in performing reliable antimicrobial susceptibility testing, as described previously.

Penicillin is the drug of choice for susceptible, $\beta$-lactamase-negative strains of coagulase-negative staphylococci. If the organism is resistant to penicillin, but truly susceptible to the PRP groups, then therapy with nafcillin, oxacillin, or cephalothin is effective $(64,95$; Dunne and Franson, Clin. Microbiol. Newsl. 8:37-42, 1986). Vancomycin is the drug of choice for PRP-resistant coagulase-negative staphylococci and for patients who are allergic to penicillin. Given the extremely high frequency of PRP-resistant $S$. epidermidis isolated from patients with prosthetic valve endocarditis and other serious hospital-acquired infections, Karchmer et al. (82) have recommended that vancomycin be used empirically for the treatment of $S$. epidermidis infections, pending the results of accurate susceptibility testing. Furthermore, these investigators demonstrated that the addition of either rifampin or gentamicin enhanced the efficacy of vancomycin when used in the treatment of prosthetic valve endocarditis due to PRP-resistant $S$. epidermidis (82). Alternative antibiotics are currently being investigated that may be useful against multiresistant isolates of coagulase-negative staphylococci. These include newer agents such as teichoplanin and the quinolone derivatives and older antibiotics such as coumeromycin, fosfomycin, fusidic acid, and novobiocin $(13,51,64,164)$. Continued study of resistance mechanisms is essential to help predict and prevent the emergence of resistance to new as well as old antistaphylococcal agents.

\section{PREVENTION}

Frequent handwashing by all health care personnel is of primary importance in limiting staff-to-patient and patientto-patient spread of coagulase-negative staphylococci (20, $33,73,97,127)$. Limiting intraoperative bacterial contamination by meticulous surgical technique, proper preoperative skin preparation, and proper draping of the operative site are all important in minimizing the risk of surgical infections $(33,73,102)$. In addition, operating room staff with infections of the hands or arms should not be allowed to participate in surgical procedures no matter how minor the infections $(20,33,102)$. Strict attention to protocols for the insertion and management of intravenous and arterial catheters are clearly important in decreasing the risk of catheterrelated infections (97). Daily surveillance of all intravascular lines and limiting the duration of placement of peripheral venous catheters to $72 \mathrm{~h}$ can greatly reduce the risk of catheter-related infections (97). Because of the importance of adherence in coagulase-negative staphylococcal prosthetic device-related infections, several investigators have suggested that production of catheters and other implants which are resistant to bacterial adherence may be an effective means of preventing these infections $(62,64,86,116$, 120, 139, 143; Dunne and Franson, Clin. Microbiol. Newsl. 8:37-42, 1986). Unfortunately, the antiadhesive surfaces of a variety of implants are neutralized by conditioning films, composed of host proteins and other materials, which immediately coat the surface of the device upon implantation (62). Given that there is a "race for the surface" between tissue cell integration and microbial colonization of the implanted device, an alternative strategy for decreasing bacterial colonization might be to develop a biomaterial that is adhesive for the appropriate tissue cells and that encour- 
ages rapid eucaryotic colonization over bacterial colonization (62). Use of prophylactic antibiotics during the vulnerable period before tissue integration of the implant surface and when the risk of random bacterial colonization is highest seems rational but is without any proven benefit and may, in fact, have significant adverse consequences $(3,4,7,34)$.

The findings of Wade et al. (162) in granulocytopenic cancer patients suggests that the addition of vancomycin to the prophylactic oral nonabsorbable antibiotic regimen reduced alimentary tract colonization with coagulase-negative staphylococci and resulted in a decline in both bacteremic and nonbacteremic infections due to $S$. epidermidis. While this is encouraging, there are little, if any, additional data to support the routine use of prophylactic vancomycin in these patients.

Although the benefits of antistaphylococcal prophylaxis in cardiac and orthopedic surgery remain uncertain, it has become standard practice to use such prophylaxis $(20,68$, $80)$. The value of antimicrobial prophylaxis in cardiac surgery has never been tested in a placebo-controlled trial, and there is very little information available on infection rates in patients not receiving antibiotics. A study by Archer and Tenenbaum (7) demonstrated that widespread use of antibiotics for prophylaxis in cardiac surgery patients led to an increased prevalence of methicillin resistance in $S$. epidermidis isolates obtained from these patients. Furthermore, these investigators found that a high percentage of the methicillin-resistant postoperative isolates were also resistant to multiple antibiotics: penicillin, nafcillin, cephalosporins, and aminoglycosides (7). Subsequently, Archer and Armstrong (4) found that cardiac surgery patients receiving a combination of rifampin and nafcillin prophylaxis became colonized with strains of $S$. epidermidis resistant not only to rifampin and nafcillin but also to gentamicin. The antibiotic resistance patterns shown by $S$. epidermidis isolates in these studies were similar to those found in isolates from cases of $S$. epidermidis prosthetic valve endocarditis in other studies (3). Clearly antibiotic prophylaxis changed the coagulasenegative flora by selecting for multiply resistant strains capable of causing serious postoperative infections $(3,4,7)$. In addition, the organisms may serve as a reservoir of resistant strains which can be transferred from patient to staff, staff to patient, and among patients within the hospital $(3-5,7,47,52,78,129,131,153)$. Thus, despite the increasing importance of coagulase-negative staphylococci as agents of nosocomial infection, it is not at all clear that antimicrobial prophylaxis is indicated or desirable. Certainly, further clinical and experimental studies are needed. Ideally, the prevention of coagulase-negative staphylococcal infections should be based on better understanding of the epidemiology, hospital reservoirs, mechanism of transmission, and host defenses against these organisms, particularly those associated with foreign devices.

\section{ACKNOWLEDGMENT}

We thank Linda Buckner for excellent secretarial support.

\section{LITERATURE CITED}

1. Aasen, J., and P. Oeding. 1971. Antigenic studies on Staphylococcus epidermidis. Acta Pathol. Microbiol. Scand. Sect. B 79:827-834.

2. Almeida, R. J., J. H. Jorgensen, and J. E. Johnson. 1983. Evaluation of the Auto Microbic System Gram-Positive Identification Card for species identification and coagulase-negative staphylococci. J. Clin. Microbiol. 18:438-439.

3. Archer, G. 1978. Antimicrobial susceptibility and selection of resistance among Staphylococcus epidermidis isolates recovered from patients with infections of indwelling foreign devices. Antimicrob. Agents Chemother. 14:353-359.

4. Archer, G. L., and B. C. Armstrong. 1983. Alterations of staphylococcal flora in cardiac surgery patients receiving antibiotic prophylaxis. J. Infect. Dis. 147:642-649.

5. Archer, G. L., D. R. Dietrick, and J. L. Johnston. 1985. Molecular epidemiology of transmissible gentamicin resistance among coagulase-negative staphylococci in a cardiac surgery unit. J. Infect. Dis. 151:243-251.

6. Archer, G. L., A. W. Karchmer, N. Vishniavsky, and J. L. Johnston. 1984. Plasmid-pattern analysis for the differentiation of infecting from noninfecting Staphylococcus epidermidis. J. Infect. Dis. 149:913-920.

7. Archer, G. L., and M. J. Tenenbaum. 1980. Antibiotic-resistant Staphylococcus epidermidis in patients undergoing cardiac surgery. Antimicrob. Agents Chemother. 17:269-272.

8. Baddour, L. M., and G. D. Christensen. 1987. Prosthetic valve endocarditis due to small-colony staphylococcal variants. Rev. Infect. Dis. 9:1168-1174.

9. Baddour, L. M., D. L. Smalley, A. P. Kraus, Jr., W. J. Lamoreaux, and G. D. Christensen. 1986. Comparison of microbiologic characteristics of pathogenic and saprophytic coagulase-negative staphylococci from patients on continuous ambulatory peritoneal dialysis. Diagn. Microbiol. Infect. Dis. 5:197-205.

10. Baird-Parker, A. C. 1963. A classification of micrococci and staphylococci based on physiological and biochemical tests. J. Gen. Microbiol. 30:409-427.

11. Baker, J. S. 1984. Comparison of various methods for differentiation of staphyloccocci and micrococci. J. Clin. Microbiol. 19:875-879.

12. Baker, J. S. 1986. Differentiation of micrococci from coagulase-negative staphylococci, p. 27-33. In P. A. Mardh and K. H. Schleifer (ed.), Coagulase-negative staphylococci. Almqvist and Wiksell International, Stockholm.

13. Barry, A. L., and R. N. Jones. 1987. In vitro activity of ciprofloxacin against gram-positive cocci. Am. J. Med. 82(Suppl. 4A):27-32.

14. Baum, J. L. 1978. Ocular infections. N. Engl. J. Med. 299:2831.

15. Bentley, D. W., R. Haque, R. A. Murphy, and M. H. Lepper. 1968. Biotyping, an epidemiological tool for coagulase-negative staphylococci, p. 54-59. Antimicrob. Agents Chemother. 1967.

16. Birnboim, H. C., and J. Doly. 1979. A rapid alkaline extraction procedure for screening recombinant plasmid DNA. Nucleic Acids Res. 7:1513-1523.

17. Bjornson, H. S., R. Colley, R. H. Bower, V. P. Duty, J. T. Schwartz-Fulton, and J. E. Fischer. 1982. Association between microorganism growth at the catheter insertion site and colonization of the catheter in patients receiving total-parenteralnutrition. Surgery 92:720-726.

18. Bor, D. H., R. M. Rose, J. F. Modlin, R. Weintraub, and G. H. Friedland. 1983. Mediastinitis after cardiovascular surgery. Rev. Infect. Dis. 5:885-897.

19. Brauner, L., P. Simonsen, and P. B. Bygren. 1986. Peritonitis caused by Staphylococcus epidermidis in patients undergoing continuous ambulatory peritoneal dialysis, p. 189-193. In P. A. Mardh and K. H. Schleifer (ed.), Coagulase-negative staphylococci. Almqvist and Wiksell International, Stockholm.

20. Burke, J. P. 1986. Infections of cardiac and vascular prostheses, p. 437-451. In J. V. Bennett and P. S. Brachman (ed.), Hospital infections. Little, Brown, \& Co., Boston.

21. Bykowska, K., A. Ludwicka, Z. Wegrzynowicz, S. Lopaciak, and M. Kopec. 1985. Anticoagulent properties of extracellular slime substance produced by Staphylococcus epidermidis. Thromb. Haemostasis 54:853-856.

22. Chambers, H. F. 1987. Coagulase-negative staphylococci resistant to $\beta$-lactam antibiotics in vivo produce penicillinbinding protein 2a. Antimicrob. Agents Chemother. 31:19191924.

23. Cheesbrough, J. S., R. G. Finch, and R. P. Burden. 1986. A 
prospective study of the mechanisms of infection associated with hemodialysis catheters. J. Infect. Dis. 154:569-589.

24. Christensen, G. D., L. M. Baddour, and W. A. Simpson. 1987. Phenotypic variation of Staphylococcus epidermidis slime production in vitro and in vivo. Infect. Immun. 55:2870-2877.

25. Christensen, G. D., A. L. Bisno, J. T. Parisi, B. McLaughlin, M. G. Hester, and R. W. Luther. 1982. Nosocomial septicemia due to multiple antibiotic-resistant Staphylococcus epidermidis. Ann. Intern. Med. 96:1-10.

26. Christensen, G. D., J. T. Parisi, A. L. Bisno, W. A. Simpson, and E. H. Beachey. 1983. Characterization of clinically significant strains of coagulase-negative staphylococci. J. Clin. Microbiol. 18:258-269.

27. Christensen, G. D., W. A. Simpson, A. L. Bisno, and E. H. Beachey. 1982. Adherence of slime-producing strains of Staphylococcus epidermidis to smooth surfaces. Infect. Immun. 37: 318-326.

28. Christensen, G. D., W. A. Simpson, A. L. Bisno, and E. H. Beachey. 1983. Experimental foreign body infections in mice challenged with slime-producing Staphylococcus epidermidis. Infect. Immun. 40:407-410.

29. Christensen, G. D., W. A. Simpson, J. J. Younger, L. M. Baddour, F. F. Barrett, D. M. Melton, and E. H. Beachey. 1985. Adherence of coagulase-negative staphylococci to plastic culture plates: a quantitative model for the adherence of staphylococci to medical devices. J. Clin. Microbiol. 22:996-1006.

30. Corman, L. C., and M. E. Levisin. 1975. Sustained bacteremia and transvenous cardiac pacemakers. J. Am. Med. Assoc. 233:264-266.

31. Coudron, P. E., D. L. Jones, H. P. Dalton, and G. L. Archer. 1986. Evaluation of laboratory tests for detection of methicillin-resistant Staphylococcus aureus and Staphylococcus epidermidis. J. Clin. Microbiol. 24:764-769.

32. Crouch, S. F., T. A. Pearson, and D. M. Parham. 1987. Comparison of modified Minitek System with Staph-Ident System for species identification of coagulase-negative staphylococci. J. Clin. Microbiol. 25:1626-1628.

33. Cruse, P. 1986. Surgical infection: incisional wounds, p. 423 436. In J. V. Bennett and P. S. Brachman (ed.), Hospital infections. Little, Brown, \& Co., Boston.

34. Dandalides, P. C., W. A. Rutala, C. A. Thomann, and F. A. Sarubbi. 1986. Serious postoperative infections caused by coagulase-negative staphylococci: an epidemiological and clinical study. J. Hosp. Infect. 8:233-241.

35. Davenport, D. S., R. M. Massanari, M. A. Pfaller, M. J. Bale, S. A. Streed, and W. J. Heirholzer, Jr. 1986. Usefulness of a test for slime production as a marker for clinically significant infections with coagulase-negative staphylococcus. J. Infect. Dis. 153:332-339.

36. Dean, B. A., R. E. O. Williams, F. Hall, and J. Corse. 1973 Phage typing of coagulase-negative staphylococci and micrococci. J. Hyg. 71:261-270.

37. de Saxe, M. J., J. A. Crees-Morris, R. R. Marples, and J. F. Richardson. 1981. Evaluation of current phage-typing systems for coagulase-negative staphylococci, p. 197-204. In J. Jeljaszewicz (ed.), Staphylococci and staphylococcal infections. Gustave Fischer Verlag, Stuttgart, Federal Republic of Germany.

38. Diaz-Mitoma, F., G. K. M. Harding, D. J. Hoban, R. S. Roberts, and D. E. Low. 1987. Clinical significance of a test for slime production in ventriculoperitoneal shunt infections caused by coagulase-negative staphylococci. J. Infect. Dis. 156:555-560.

39. Doern, G. V., J. E. Earls, P. A. Jeznaih, and D. S. Parker. 1983. Species identification and biotyping of staphylococci by the API Staph-Ident system. J. Clin. Microbiol. 17:260-263.

40. Dunne, W. M., Jr., D. B. Nelson, and M. J. Chusid. 1987. Epidemiologic markers of pediatric infections caused by coagulase-negative staphylococci. Pediatr. Infect. Dis. J. 6:10311035.

41. Eisenberg, E. S., M. Ambalu, G. Szylagi, V. Aning, and R. Soeiro. 1987. Colonization of skin and development of peritonitis due to coagulase-negative staphylococci in patients un- dergoing peritoneal dialysis. J. Infect. Dis. 156:478-482.

42. Eng, R. H. K., C. Wang, A. Person, T. E. Kiehn, and D. Armstrong. 1982. Species identification of coagulase-negative staphylococcal isolates from blood cultures. J. Clin. Microbiol. 15:439-442.

43. Evans, J. B., W. L. Bradford, and C. F. Niven. 1955. Comments concerning the taxonomy of the genera Micrococcus and Staphylococcus. Int. Bull. Bacteriol. Nomencl. 5:61-66.

44. Falk, D., and S. J. Guering. 1983. Differentiation of Staphylococcus and Micrococcus spp. with the Taxo A bacitracin disk. J. Clin. Microbiol. 18:719-721.

45. Faller, A., and K. Schleifer. 1981. Modified oxidase and benzidine tests for separation of staphylococci from micrococci. J. Clin. Microbiol. 13:1031-1035.

46. Fleer, A., L. J. Gerards, P. Aerts, N. A. C. Westerdaal, R. C. Senders, H. van Dijk, and J. Verhoef. 1985. Opsonic defense to Staphylococcus epidermidis in the premature neonate. J. Infect. Dis. 152:930-937.

47. Forbes, B. A., and D. R. Schaberg. 1983. Transfer of resistance plasmids from Staphylococcus epidermidis to Staphylococcus aureus: evidence for conjugative exchange of resistance. J. Bacteriol. 153:627-634.

48. Forse, R. A., C. Dixon, K. Bernard, L. Martinez, A. P. H. McLean, and J. L. Meakins. 1979. Staphylococcus epidermidis: an important pathogen. Surgery 86:507-514.

49. Freeman, J., R. Platt, D. G. Sidebottom, J. M. LeClair, M. F. Epstein, and D. A. Goldman. 1987. Coagulase-negative staphylococcal bacteremia in the changing neonatal intensive care unit population. J. Am. Med. Assoc. 258:2548-2552.

50. Gahrn-Hansen, B. 1987. Coagulase-negative staphylococci and microcci in clinical microbiology. Dan. Med. Bull. 34:96-114.

51. Galetto, D. W., J. A. Boscia, W. D. Kobasa, and D. Kaye. 1986. Teichoplanin compared with vancomycin for treatment of experimental endocarditis due to methicillin-resistant Staphylococcus epidermidis. J. Infect. Dis. 154:69-75.

52. Galetto, D. W., J. L. Johnston, and G. L. Archer. 1987. Molecular epidemiology of trimethoprim resistance among coagulase-negative staphylococci. Antimicrob. Agents Chemother. 31:1683-1688.

53. Gemmell, C. G. 1986. Virulence characteristics of Staphylococcus epidermidis. J. Med. Microbiol. 22:287-289.

54. Gemmell, C. G., and J. E. Dawson. 1982. Identification of coagulase-negative staphylococci with the API Staph system. J. Clin. Microbiol. 16:874-877.

55. Gemmell, C. G., and C. E. Roberts. 1973. Toxins and enzymes of coagulase-negative staphylococci isolated from human infections. J. Hyg. Epidemiol. Microbiol. Immunol. 18:261-266.

56. Gemmell, C. G., and F. Schumacher-Perdreau. 1986. Extracellular toxins and enzymes elaborated by coagulase-negative staphylococci, p. 109-121. In P. A. Mardh and K. H. Schleifer (ed.), Coagulase-negative staphylococci. Almqvist and Wiksell International, Stockholm.

57. Giger, O., C. C. Charilaou, and K. R. Cundy. 1984. Comparison of the API Staph-Ident and DMS Staph-Trac systems with conventional methods used for the identification of coagulasenegative staphylococci. J. Clin. Microbiol. 19:68-72.

58. Gill, V. J., C. B. Manning, and C. M. Ingalls. 1981. Correlation of penicillin minimum inhibitory concentrations and penicillin zone edge appearance with staphylococcal beta-lactamase production. J. Clin. Microbiol. 14:437-440.

59. Gill, V. J., S. T. Selepak, and E. C. Williams. 1983. Species identification and antibiotic susceptibilities of coagulase-negative staphylococci isolated from clinical specimens. J. Clin. Microbiol. 18:1314-1319.

60. Grasmick, A. E., N. Naito, and D. A. Bruckner. 1983. Clinical comparison of the AutoMicrobic System Gram-Positive Identification Card, API Staph-Ident, and conventional methods in the identification of coagulase-negative Staphylococcus spp. J. Clin. Microbiol. 18:1323-1328.

61. Gray, E. D., G. Peters, M. Verstegen, and W. E. Regelmann. 1984. Effect of extracellular slime substance from Staphylococcus epidermidis on the human cellular immune response. Lancet i:365-367. 
62. Gristina, A. G. 1987. Biomaterial-centered infection: microbial adhesion versus tissue integration. Science 237:1588-1595.

63. Hamilton-Miller, J. M. T., and A. Iliffe. 1985. Antimicrobial resistance in coagulase-negative staphylocci. J. Med. Microbiol. 19:217-226.

64. Hamory, B. H., and J. T. Parisi. 1987. Staphylococcus epidermidis: a significant nosocomial pathogen. Am. J. Infect. Control 15:59-74.

65. Hansen, B. G. 1983. Population analysis of susceptibility to methicillin, vancomycin, and three cephalosporins in two methicillin-resistant strains of Staphylococcus epidermidis. Acta Pathol. Microbiol. Immunol. Scand. Sect. B 91:279-284.

66. Hawkey, P. M. 1987. Molecular methods for the investigation of bacterial cross-infection. J. Hosp. Infect. 9:211-218.

67. Hedstrom, S. A. 1986. Sepsis and septicaemia caused by coagulase-negative staphylococci, p. 171-178. In P. A. Mardh and K. H. Scheifer (ed.), Coagulase-negative staphylococci. Almqvist and Wiksell International, Stockholm.

68. Hirschmann, J. V., and T. S. Inui. 1980. Antimicrobial prophylaxis: a critique of recent trials. Rev. Infect. Dis. 2:1-23.

69. Hogt, A. H., J. Dankert, J. A. DeVries, and J. Feijen. 1983. Adhesion of coagulase-negative staphylococci to biomaterials. J. Gen. Microbiol. 129:2959-2968.

70. Hogt, A. H., J. Dankert, and J. Feijen. 1983. Adhesion of coagulase-negative staphylococci to methacrylate polymers and co-polymers. J. Biomed. Materials Res. 20:533-545.

71. Hogt, A. H., J. Dankert, C. F. Hulstaert, and J. Feijen. 1986. Cell surface characteristics of coagulase-negative staphylococci and their adherence to fluorinated poly(ethylenepropylene). Infect. Immun. 51:201-301.

72. Holt, R. 1969. The classification of staphylococci from colonized ventriculo-atrial shunts. J. Clin. Pathol. 22:475-482.

73. Houang, E. T., R. R. Marples, I. Weir, A. J. Mourant, M. J. de Saxe, and B. Singleton. 1986. Problems in the investigation of an apparent outbreak of coagulase-negative staphylococcal septicaemia following cardiac surgery. J. Hosp. Infect. 8:224 232.

74. Hussain, Z., L. Stoakes, D. L. Stevens, B. C. Schieven, R. Lannigan, and C. Jones. 1986. Comparison of the MicroScan system with the API Staph-Ident system for species identification of coagulase-negative staphylococci. J. Clin. Microbiol. 23:126-128.

75. Hutton, J. P., B. H. Hamory, J. T. Parisi, and L. J. Strausbaugh. 1985. Staphylococcus epidermidis arthritis following catheter induced bacteremia in a neutropenic patient. Diagn. Microbiol. Infect. Dis. 3:119-124.

76. Ishak, M. A., D. H. M. Groschel, G. L. Mandell, and R. P. Wenzel. 1985. Association of slime with pathogenicity of coagulase-negative staphylococci causing nosocomial septicemia. J. Clin. Microbiol. 22:1025-1029.

77. Iwantscheff, A., E. Kuhnen, and H. Brandis. 1985. Species distribution of coagulase-negative staphylococci isolated from clinical sources. Zentralbl. Bakteriol. Parasitenkd. Infektionskr. Hyg. Abt. 1 Orig. Reihe A 260:41-50.

78. Jaffe, H. W., H. M. Sweeney, C. Nathan, R. A. Weinstein, S. A. Kabins, and S. Cohen. 1980. Identity and interspecific transfer of gentamicin-resistance plasmids in Staphylococcus aureus and Staphylococcus epidermidis. J. Infect. Dis. 141:738-747.

79. Johnson, G. M., D. A. Lee, W. E. Regelmann, E. D. Gray, G. Peters, and P. G. Quie. 1986. Interference with granulocyte function by Staphylococcus epidermidis slime. Infect. Immun. 54:13-20.

80. Kaiser, A. B. 1986. Antimicrobial prophylaxis in surgery. N. Engl. J. Med. 315:1129-1138.

81. Kamme, C., and L. Lindberg. 1981. Aerobic and anaerobic bacteria in deep infections after total hip arthroplasty: differential diagnosis. Clin. Orthop. 154:202-207.

82. Karchmer, A. W., G. L. Archer, and W. E. Dismukes. 1983. Staphylococcus epidermidis causing prosthetic valve endocarditis: microbiologic and clinical observations as guides to therapy. Ann. Intern. Med. 98:447-455.

83. Karp, J. E., J. D. Dick, C. Angelopulos, P. Charache, L. Green, P. J. Burke, and R. Saral. 1986. Empiric use of vancomycin during prolonged treatment-induced granulocytopenia. Am. J. Med. 81:237-242.

84. Kauffman, C. A., J. N. Sheagren, and P. G. Quie. 1984. Staphylococcus epidermidis mediastinitis and disseminated intravascular coagulation. Ann. Intern. Med. 100:60-61.

85. Keane, W. F., C. M. Comty, H. A. Verbrugh, and P. K. Peterson. 1984. Opsonic deficiency of peritoneal dialysis effluent in continuous ambulatory peritoneal dialysis. Kidney Int. 25:539-543.

86. Kingston, D., D. V. Seal, and I. D. Hill. 1986. Self-disinfecting plastics for intravenous catheters and prosthetic inserts. J. Hyg. 96:185-198.

87. Kloos, W. E. 1980. Natural populations of the genus Staphylococcus. Annu. Rev. Microbiol. 34:559-592.

88. Kloos, W. E. 1986. Ecology of human skin, p. 37-50. In P. A. Mardh and K. H. Schleifer (ed.), Coagulase-negative staphylococci. Almqvist and Wiksell International, Stockholm.

89. Kloos, W. E., and J. H. Jorgensen. 1985. Staphylococci, p. 143-153. In E. H. Lennette, A. Balows, W. J. Hausler, Jr., and H. J. Shadomy (ed.), Manual of clinical microbiology, 4th ed. American Society for Microbiology, Washington, D.C.

90. Kloos, W. E., and M. S. Musselwhite. 1975. Distribution and persistence of Staphylococcus and Micrococcus species and other aerobic bacteria on human skin. Appl. Microbiol. 30: 381-395.

91. Kloos, W. E., and K. H. Schleifer. 1975. Simplified scheme for routine identification of human Staphylococcus species. J. Clin. Microbiol. 1:82-88.

92. Kloos, W. E., and J. F. Wolfshohl. 1982. Identification of Staphylococcus species with the API Staph-Ident system. J. Clin. Microbiol. 16:509-516.

93. Kristinsson, K. G., R. C. Spencer, and C. B. Brown. 1986. Clinical importance of production of slime by coagulasenegative staphylococci in chronic ambulatory peritoneal dialysis. J. Clin. Pathol. 39:117-118.

94. Linares, J., A. Sitges-Serra, J. Garau, J. L. Perez, and R. Martin. 1985. Pathogenesis of catheter sepsis: a prospective study with quantitative and semiquantititive cultures of catheter hub and segments. J. Clin. Microbiol. 25:357-360.

95. Lowy, F. D., and S. M. Hammer. 1983. Staphylococcus epidermidis infections. Ann. Intern. Med. 99:834-839.

96. Madiraju, M. V. V. S., D. P. Brunner, and B. J. Wilkinson. 1987. Effects of temperature, $\mathrm{NaCl}$, and methicillin on penicillin-binding proteins, growth, peptidoglycan synthesis, and autolysis in methicillin-resistant Staphylococcus aureus. Antimicrob. Agents Chemother. 31:1727-1733.

97. Maki, D. G. 1982. Infections associated with intravascular lines, p. 309-363. In J. S. Remington and M. N. Swartz (ed.), Current clinical topics in infectious diseases, vol. 3. McGrawHill Book Co., New York.

98. Males, B. M., W. A. Rogers, and J. T. Parisi. 1975. Virulence factors of biotypes of Staphylococcus epidermidis from clinical sources. J. Clin. Microbiol. 1:256-261.

99. Mankoth, J., and G. Wohl. 1984. Hybridization of nucleic acids immobilized on solid supports. Anal. Biochem. 138:267-284.

100. Marples, R. R. 1986. Laboratory assessment in the epidemiology of infections caused by coagulase-negative staphylococci. J. Med. Microbiol. 22:285-287.

101. Marrie, T. J., C. Kwan, M. A. Nobel, A. West, and L. Duffield. 1982. Staphylococcus saprophyticus as a cause of urinary tract infection. J. Clin. Microbiol. 16:427-431.

102. Mayhall, C. G. 1987. Surgical infections including burns, p. 344-384. In R. P. Wenzel (ed.), Prevention and control of nosocomial infections. The Williams \& Wilkins Co., Baltimore.

103. McDougal, L. K., and C. Thornsberry. 1984. New recommendations for disk diffusion antimicrobial susceptibility tests for methicillin-resistant (heteroresistant) staphylococci. J. Clin. Microbiol. 19:482-488.

104. McDougal, L. K., and C. Thornsberry. 1986. The role of $\beta$-lactamase in staphylococcal resistance to penicillinase-resistant penicillins and cephalosporins. J. Clin. Microbiol. 23:832839. 
105. Meyers, J. A., D. Sanchez, L. P. Elwell, and S. Falkow. 1976. Simple agarose gel electrophoretic method for the identification and characterization of plasmid deoxyribonucleic acid. J. Bacteriol. 127:1529-1537.

106. Mickelsen, P. A., J. J. Plorde, K. P. Gordon, C. Hargiss, J. McClure, F. D. Schoenknecht, F. Condie, F. C. Tenover, and L. S. Tompkins. 1985. Instability of antibiotic resistance in a strain of Staphylococcus epidermidis isolated from an outbreak of prosthetic valve endocarditis. J. Infect. Dis. 152:50-58.

107. Morrison, A. J., C. V. Freer, M. A. Searcy, S. M. Landry, and R. P. Wenzel. 1986. Nosocomial bloodstream infections: secular trends in a statewide surveillance program in Virginia. Infect. Control 7:550-553.

108. Needham, C. A., and W. Stempsey. 1984. Incidence, adherence, and antibiotic resistance of coagulase-negative Staphylococcus species causing human disease. Diagn. Microbiol. Infect. Dis. 2:293-299.

109. Noble, M. A., P. E. Reid, C. M. Park, and V. Y. H. Chan. 1986. Inhibition of human neutrophil bacteriocidal activity by extracellular substance from slime-producing Staphylococcus epidermidis. Diagn. Microbiol. Infect. Dis. 4:335-340.

110. Oeding, P. 1983. Taxonomy and identification, p. 1-31. In C. S. F. Easmon (ed.), Staphylococci and staphylococcal infections, vol. 1. Academic Press, Inc., New York.

111. Parisi, J. T. 1985. Coagulase-negative staphylococci and the epidemiological typing of Staphylococcus epidermidis. Microbiol. Rev. 49:126-139.

112. Parisi, J. T. 1986. Epidemiologic markers in Staphylococcus epidermidis infections, p. 139-144. In L. Leive (ed.), Microbiology-1986. American Society for Microbiology, Washington, D.C.

113. Parisi, J. T., and D. W. Hecht. 1980. Plasmid profiles in epidemiologic studies of infections by Staphylococcus epidermidis. J. Infect. Dis. 141:637-643.

114. Parisi, J. T., B. C. Lampson, D. L. Hoover, and J. A. Khan. 1986. Comparison of epidemiologic markers for Staphylococcus epidermidis. J. Clin. Microbiol. 24:56-60.

115. Parisi, J. T., H. W. Talbot, Jr., and J. M. Skahan. 1978. Development of a phage typing set for Staphylococcus epidermidis in the United States. Zentralbl, Bakteriol. Parasitenkd. Infektionskr. Hyg. Abt. 1 Orig. Reihe A 241:60-67.

116. Pascual, A., A. Fleer, N. A. C. Westerdaal, and J. Verhoef. 1986. Modulation of adherence of coagulase-negative staphylococci to Teflon catheters in vitro. Eur. J. Clin. Microbiol. 5:518-522.

117. Pereira, A. T. 1962. Coagulase-negative strains of Staphylococcus possessing antigen 51 as agents of urinary tract infection. J. Clin. Pathol. 15:252-253.

118. Peters, G. 1986. Adherence of Staphylococcus epidermidis to plastic devices. J. Med. Microbiol. 22:289-291.

119. Peters, G., R. Locci, and G. Pulverer. 1982. Adherence and growth of coagulase-negative staphylococci on surfaces of intravenous catheters. J. Infect. Dis. 146:479-482.

120. Peters, G., and G. Pulverer. 1984. Pathogenesis and management of Staphylococcus epidermidis "plastic" foreign body infections. J. Antimicrob. Chemother. 14(Suppl. D):67-71.

121. Peterson, P. K., G. Matzke, and W. F. Keane. 1987. Current concepts in the management of peritonitis in patients undergoing continuous ambulatory peritoneal dialysis. Rev. Infect. Dis. 9:604-612.

121a.Pfaller, M., D. Davenport, M. Bale, M. Barrett, F. Koontz, and R. M. Massanari. 1988. Development of the quantitative microtest for slime production by coagulase-negative staphylococci. Eur. J. Clin. Microbiol. Infect. Dis. 7:30-33.

122. Ponce De Leon, S., S. H. Guenther, and R. P. Wenzel. 1986. Microbiologic studies of coagulase-negative staphylococci isolated from patients with nosocomial bacteraemias. J. Hosp. Infect. 7:121-129.

123. Ponce De Leon, S., and R. P. Wenzel. 1984. Hospital-acquired bloodstream infections with Staphylococcus epidermidis. Am. J. Med. 77:639-644.

124. Powell, M., and P. J. Sanderson. 1987. Resistant coagulasenegative staphylococci in hospital patients. J. Hosp. Infect.
9:48-53.

125. Pulverer, G., J. Pillich, and M. Krivankova. 1973. Differentiation of coagulase-negative staphylococci by bacterophage typing, p. 503-508. In J. Jeljaszewicz (ed.), Staphylococci and staphylococcal infections. S. Karger, Basel.

126. Reifsteck, F., S. Wee, and B. J. Wilkinson. 1987. Hydrophobicity-hydrophilicity of staphylococci. J. Med. Microbiol. 24: 65-73.

127. Reybrouck, G. 1986. Handwashing and hand disinfection. J. Hosp. Infect. 8:5-23.

128. Ruoff, K. L., M. J. Ferraro, M. E. Jerz, and J. Kissling. 1982. Automated identification of gram-positive bacteria. J. Clin. Microbiol. 16:1091-1095.

129. Sattler, F. R., J. B. Foderaro, and R. C. Aber. 1984. Staphylococcus epidermidis bacteremia associated with vascular catheters: an important cause of febrile morbidity in hospitalized patients. Infect. Control 5:279-284.

130. Schaberg, D. R., and M. Zervos. 1986. Plasmid analysis in the study of the epidemiology of nosocomial gram-positive cocci. Rev. Infect. Dis. 8:705-712.

131. Schaberg, D. R., and M. J. Zervos. 1986. Intergeneric and interspecies gene exchange in gram-positive cocci. Antimicrob. Agents Chemother. 30:817-822.

132. Schleifer, K. H. 1986. Taxonomy of coagulase-negative staphylococci, p. 11-26. In P. A. Mardh and K. H. Schleifer (ed.), Coagulase-negative staphylococci. Almqvist and Wiksell International, Stockholm.

133. Schleifer, K. H., and M. Kocur. 1973. Classification of staphylococci based on chemical and biochemical properties. Arch. Microbiol. 93:65-85.

134. Schleifer, K. H., S. A. Meyer, and M. Rupprecht. 1979. Relatedness among coagulase-negative staphylococci: deoxyribonucleic acid reassociation and comparative immunological studies. Arch. Microbiol. 122:93-101.

135. Schoenbaum, S. C., P. Gardner, and J. Shillito. 1975. Infections of cerebrospinal fluid shunts: epidemiology, clinical manifestations, and therapy. J. Infect. Dis. 131:543-552.

136. Schwalbe, R. S., J. T. Stapleton, and P. H. Gilligan. 1987. Emergence of vancomycin resistance in coagulase-negative staphylococci. N. Engl. J. Med. 316:927-931.

137. Schwalbe, R. S., J. T. Stapleton, and P. H. Gilligan. 1987. Vancomycin-resistant Staphylococcus. N. Engl. J. Med. 317: 767-768.

138. Selepak, S. T., and F. G. Witebsky. 1984. $\beta$-Lactamase detection in nine staphylococcal species. J. Clin. Microbiol. 20:1200-1201.

139. Sewell, C. M. 1984. Coagulase-negative staphylococci and the clinical microbiology laboratory. Eur. J. Clin. Microbiol. 3:94 95.

140. Sewell, C. M., J. E. Clarridge, E. J. Young, and R. K. Guthrie. 1982. Clinical significance of coagulase-negative staphylococci. J. Clin. Microbiol. 16:236-239.

141. Sherertz, R. J., R. J. Falk, K. A. Huffman, C. A. Thomann, and W. D. Mattern. 1983. Infections associated with subclavian Uldall catheters. Arch. Intern. Med. 143:42-56.

142. Sheth, N. K., T. R. Franson, and P. G. Sohnle. 1985. Influence of bacterial adherence to intravascular catheters on in-vitro antibiotic susceptibility. Lancet ii:1266-1268.

143. Sheth, N. K., H. D. Rose, T. R. Franson, F. L. A. Buckmore, and P. G. Sohnle. 1983. In vitro quantitative adherence of bacteria to intravascular catheters. J. Surg. Res. 34:213-218.

144. Silvestri, L. G., and L. R. Hill. 1965. Agreement between deoxyribonucleic acid base composition and taxonomic classification of gram-positive cocci. J. Bacteriol. 90:136-140.

145. Skahan, J. M., and J. T. Parisi. 1977. Development of a bacteriophage typing set for Staphylococcus epidermidis. J. Clin. Microbial. 6:16-18.

146. Smith, D. J., R. L. Kaplan, W. Landau, G. M. Trenholme. 1982. Speciation and antibiotic susceptibility patterns of coagulase-negative staphylococci. Eur. J. Clin. Microbiol. 1:228232.

147. Smith, I. M. 1981. Staphylococcus epidermidis septicemia: 1974-1978 compared to 1949-1958, p. 765-772. In J. Jelijasze- 
wicz (ed). Staphylococci and staphylococcal infections. Gustav Fischer Verlag, Stuttgart, Federal Republic of Germany.

148. Smith, I. M., P. D. Beals, K. R. Kingsbury, and H. F. Hasenclever. 1958. Observations on Staphylococcus albus septicemia in mice and men. Arch. Intern. Med. 102:375-388.

149. Southern, E. M. 1975. Detection of specific sequences among DNA fragments separated by gel electrophoresis. J. Mol. Biol. 98:503-517.

150. Stevens, D. L., and C. Jones. 1984. Use of trehalose-mannitolphosphatase agar to differentiate Staphylococcus epidermidis and Staphylococcus saprophyticus from other coagulase-negative staphylococci. J. Clin. Microbiol. 20:977-980.

151. Stillman, R. I., R. P. Wenzel, and L. G. Donowitz. 1987. Emergence of coagulase-negative staphylococci as major nosocomial bloodstream pathogens. Infect. Control 8:108-112.

152. Talbot, H. W., Jr., and J. T. Parisi. 1976. Phage typing of Staphylococcus epidermidis. J. Clin. Microbiol. 3:519-523.

153. Tennent, J. M., J. W. May, and R. A. Skurray. 1984. Multiple antibiotic resistance in Staphylococcus aureus and Staphylococcus epidermidis: plasmids in strains associated with nosocomial infection. Pathology 16:250-255.

154. Tenney, J. H., M. R. Moody, K. A. Newman, S. C. Schimpif, J. C. Wade, J. W. Costerton, and W. P. Reed. 1986. Adherent microorganisms on lumenal surfaces of long-term intravenous catheters. Arch. Intern. Med. 146:1949-1954.

155. Tierno, P. M., Jr., and G. Stotzky. 1978. Serologic typing of Staphylococcus epidermidis biotype 4. J. Infect. Dis. 137:514 523.

156. Thornsberry, C., and L. K. McDongal. 1983. Successful use of broth microdilution in susceptibility tests for methicillin-resistant (heteroresistant) staphylococci. J. Clin. Microbiol. 18: 1084-1091.

157. Ubukata, K., N. Yamashita, and M. Koono. 1985. Occurrence of a beta-lactam-inducible penicillin-binding protein in methicillin-resistant staphylococci. Antimicrob. Agents Chemother. 27:851-857.

158. Van Boven, C. P. A., J. Verhoef, and K. C. Winkler. 1969. Bacteriophage typing of coagulase-negative staphylococci. Antonie van Leeuwenhoek J. Microbiol. Serol. 35:232.
159. Van Loosdrecht, M. C. M., J. Lyklema, W. Norde, G. Schraa, and A. J. B. Zehnder. 1987. The role of bacterial cell wall hydrophobicity in adhesion. Appl. Environ. Microbiol. 53: 1893-1897.

160. Verbrugh, H. A., and J. Van Der Meulen. 1986. Staphylococcus epidermidis and the CAPD host. J. Med. Microbiol. 22:291-295.

161. Wachsmuth, K. 1986. Molecular epidemiology of bacterial infections: examples of methodology and investigations of outbreaks. Rev. Infect. Dis. 8:682-692.

162. Wade, J. C., S. C. Schimpff, K. A. Newman, and P. H. Wiernik. 1982. Staphylococcus epidermidis: an increasing cause of infection in patients with granulocytopenia. Ann. Intern. Med. 97:503-508.

163. Wadstrom, T., and F. Rozgonyi. 1986. Virulence determinants of coagulase-negative staphylococci, p. 123-130. In P. A. Mardh and K. H. Schleifer (ed.), Coagulase-negative staphylococci. Almqvist and Wiksell International, Stockholm.

164. Watanakunakorn, C. 1987. In-vitro activity of teichoplanin alone and in combination with rifampicin, gentamicin or tobramycin against coagulase-negative staphylococci. J. Antimicrob. Chemother. 19:439-443.

165. Wenzel, R. P. 1986 . The reemergence of gram-positive cocci as major nosocomial pathogens. Infect. Control 7:118-119.

166. Winston, D. J., D. V. Dudnick, M. Chapin, W. G. Ho, R. P. Gale, and W. J. Martin. 1983. Coagulase-negative staphylococcal bacteremia in patients receiving immunosuppressive therapy. Arch. Intern. Med. 143:32-36.

167. Woods, G. L., G. S. Hall, I. Rutherford, K. J. Pratt, and C. C. Knapp. 1986. Detection of methicillin-resistant Staphylococcus epidermidis. J. Clin. Microbiol. 24:349-352.

168. Younger, J. J., G. D. Christensen, D. L. Bartley, J. C. H. Simmons, and F. F. Barrett. 1987. Coagulase-negative staphylococci isolated from cerebrospinal fluid shunts: importance of slime production, species identification, and shunt removal to clinical outcome. J. Infect. Dis. 156:548-554.

169. Zimmeli, W., F. A. Waldvogel, P. Vaudaux, and U. E. Nydigger. 1982. Pathogenesis of foreign body infections: description and characteristics of an animal model. J. Infect. Dis. 146:487497. 